\title{
Differential Progression of Structural and Functional Alterations in Distinct Retinal Ganglion Cell Types in a Mouse Model of Glaucoma
}

\author{
Luca Della Santina, ${ }^{1}$ Denise M. Inman, ${ }^{2}$ Caroline B. Lupien, ${ }^{2}$ Philip J. Horner, ${ }^{2}$ and Rachel O. L. Wong ${ }^{1}$ \\ ${ }^{1}$ Department of Biological Structure, University of Washington, Seattle, Washington 98195, and 'Institute for Stem Cell and Regenerative Medicine, \\ University of Washington, Seattle, Washington 98109
}

\begin{abstract}
Intraocular pressure (IOP) elevation is a principal risk factor for glaucoma. Using a microbead injection technique to chronically raise IOP for 15 or $30 \mathrm{~d}$ in mice, we identified the early changes in visual response properties of different types of retinal ganglion cells (RGCs) and correlated these changes with neuronal morphology before cell death. Microbead-injected eyes showed reduced optokinetic tracking as well as cell death. In such eyes, multielectrode array recordings revealed that four RGC types show diverse alterations in their light responses upon IOP elevation. OFF-transient RGCs exhibited a more rapid decline in both structural and functional organizations compared with other RGCs. In contrast, although the light-evoked responses of OFF-sustained RGCs were perturbed, the dendritic arbor of this cell type remained intact. ON-transient and ON-sustained RGCs had normal functional receptive field sizes but their spontaneous and light-evoked firing rates were reduced. $\mathrm{ON}$ - and OFF-sustained RGCs lost excitatory synapses across an otherwise structurally normal dendritic arbor. Together, our observations indicate that there are changes in spontaneous activity and light-evoked responses in RGCs before detectable dendritic loss. However, when dendrites retract, we found corresponding changes in receptive field center size. Importantly, the effects of IOP elevation are not uniformly manifested in the structure and function of diverse RGC populations, nor are distinct RGC types perturbed within the same time-frame by such a challenge.
\end{abstract}

\section{Introduction}

A critical step toward treating neurodegenerative diseases is to understand how different types of neurons within a region of the brain are affected in their structure and function during early stages of the disease. The retina provides a well studied model for answering this fundamental question because its multiple cell types have been well studied with respect to their morphology and function (Masland, 2001; Wässle, 2004; Sanes and Zipursky, 2010). Glaucoma is a retinal neurodegenerative disease that is the second leading cause of blindness around the world (Pascolini and Mariotti, 2012). Elevated intraocular pressure (IOP) is one of the main risk factors across species for developing glaucoma (Sommer, 1989; Rasmussen and Kaufman, 2005; Pang and Clark, 2007). Considerable effort has been dedicated in previous studies to identify the cascade of structural and functional alterations in retinal ganglion cells (RGCs) that eventually lead to their death

Received Nov. 26, 2012; revised Sept. 20, 2013; accepted Sept. 24, 2013.

Author contributions: L.D.S., D.M.I., P.J.H., and R.O.L.W. designed research; L.D.S., D.M.I., and C.B.L. performed research; L.D.S., D.M.I., and C.B.L. analyzed data; L.D.S., D.M.I., and R.O.L.W. wrote the paper.

This work was supported by the Glaucoma Research Foundation (Shaffer Grant to R.O.L.W.); NIH Grant EY EY017101 (to R.0.L.W.); Glaucoma Research Foundation Catalyst for a Cure Initiative and the Melza M. and Frank Theodore Barr Foundation to P.J. Horner. We thank Mrinalini Hoon and Felice Dunn for critical reading of this manuscript; James Demas for guidance on MEA techniques and analysis; and Sahar Manavi, John Campbell, and Jonathan Linton (National Eye Institute Vision Core Grant EY-01730) for technical assistance.

The authors declare no competing financial interests.

Correspondence should be addressed to Rachel 0. L. Wong, Department of Biological Structure, University of Washington, 1959 NE Pacific Street, Seattle, WA 98195. E-mail: wongr2@uw.edu.

DOI:10.1523/JNEUROSCI.5461-12.2013

Copyright $\odot 2013$ the authors $\quad 0270-6474 / 13 / 3317444-14 \$ 15.00 / 0$
(Calkins and Horner, 2012). Early signs of damage have been detected at the level of RGC axons involving metabolic changes, impairment of axonal transport, and downregulation of specific genes (Howell et al., 2007; Buckingham et al., 2008; Soto et al., 2008; Baltan et al., 2010). Subsequently, RGC cell bodies shrink and their dendrites are pruned before cell death (Calkins, 2012). However, it is not yet well understood what changes in visual function are first manifested in RGCs upon IOP elevation and whether there are differential effects among RGC types at the earliest stages of perturbation.

Previous studies in animal model systems of glaucoma indeed suggest that RGCs may not all be uniformly affected. Even when degeneration is advanced, zones of relatively unaffected cells can still be found (Jakobs et al., 2005; Fu and Sretavan, 2010). Moreover, dendritic arbors of some RGCs appear more affected than others at later stages of the disease (Weber et al., 1998; Pavlidis et al., 2003; Shou et al., 2003). Here, we used a mouse model of glaucoma in which IOP is elevated by an intraocular injection of polystyrene microbeads (Sappington et al., 2010). We artificially raised IOP in mice where several types of RGCs are sparsely labeled by expression of fluorescent protein (Thyl-YFP-H) (Feng et al., 2000), and compared the dendritic changes across RGC types in saline control and microbead-injected eyes. In addition, we performed multielectrode array recordings to identify four major types of RGCs with distinct responses to light (ON sustained or transient; OFF sustained or transient), and compared the responses between control and bead-injected eyes. We analyzed retinas at two stages during the period when RGC death was 
A

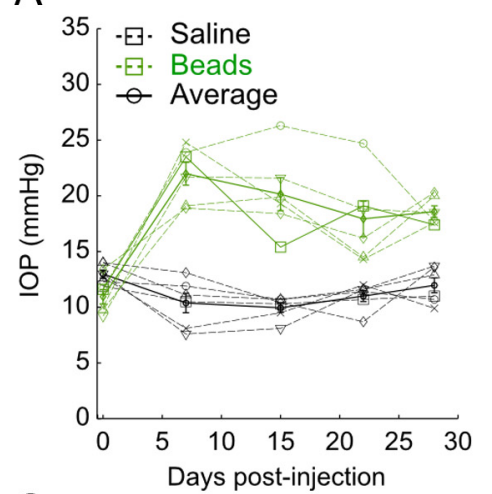

C

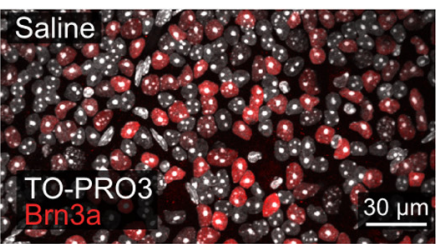

D
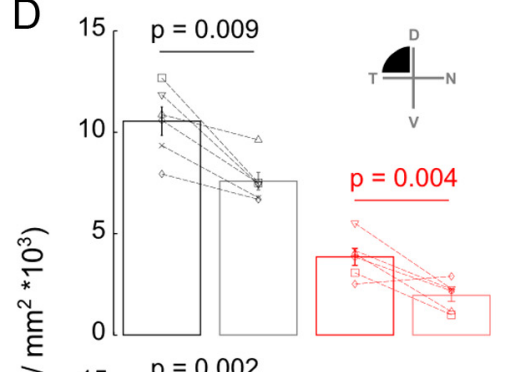

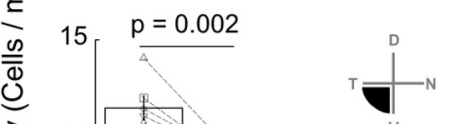

高

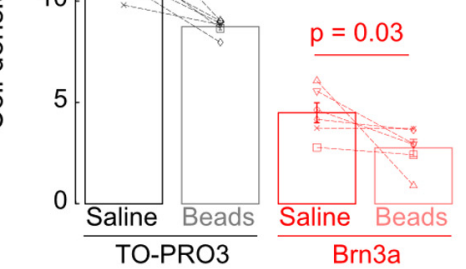

E

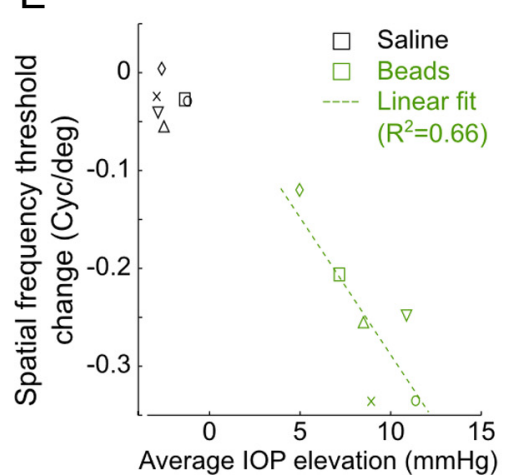

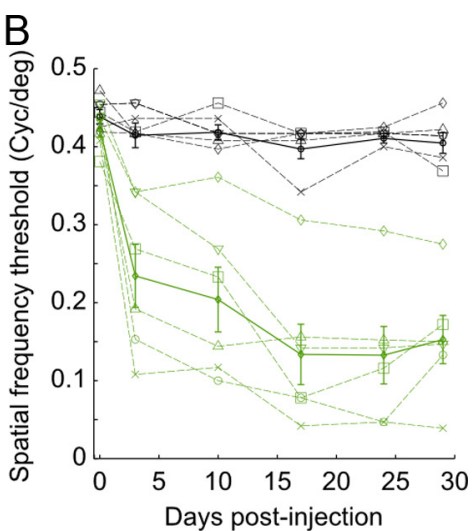

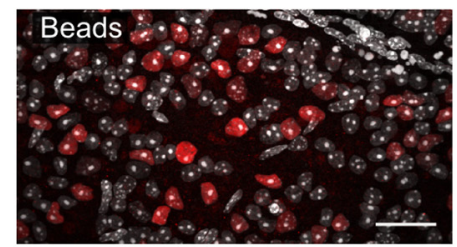

15

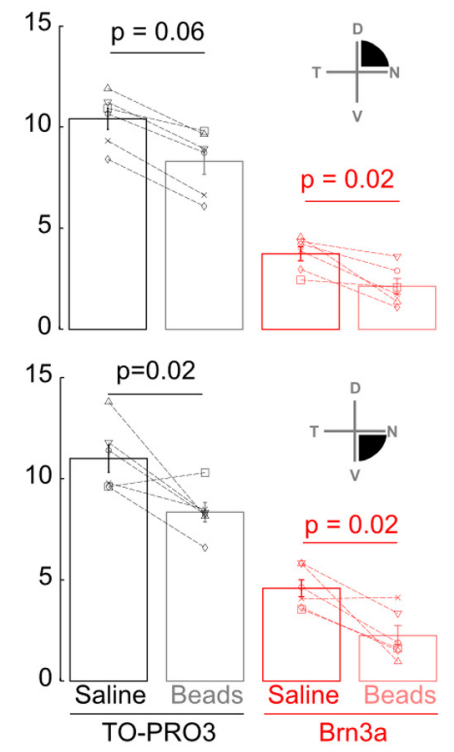

$\mathrm{F}$

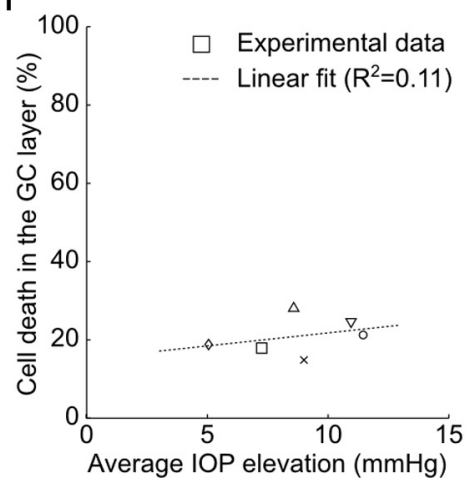

Figure 1. Correlations between IOP elevation, RGC death, and optokinetic responses of microbead-injected and control eyes. $\boldsymbol{A}$, Plots of IOP of bead- and saline-injected control eyes. Shown here are the IOP measurements for 6 animals that survived for $30 \mathrm{~d}$ after injection. Black lines and symbols are saline-injected and gray lines and symbols are bead-injected. Within each group, each animal is represented by a different symbol. The solid lines represent the averaged data for each group. $\boldsymbol{B}$, Plots of SFT for the same animals as in $\boldsymbol{A}$. C, Nuclear staining (TO-PR03, gray) and Brn3a immunostaining (red) in the GCL of control and microbead-injected eyes. $\boldsymbol{D}$, Average density of cells (gray histograms) and Brn3a + cells (red histograms) in the GCL of the retinas from $\boldsymbol{A}$ and $\boldsymbol{B}$. Each plot quantifies cell loss in a specific retinal quadrant, as shown in the inset (T, temporal; $V$, ventral; N, nasal; D, dorsal). Statistics: Wilcoxon-Mann-Whitney rank sum test. $\boldsymbol{E}$, Correlation between IOP elevation and SFT for each eye of the animals in $\boldsymbol{A}$ and $\boldsymbol{B}$. $\boldsymbol{F}$,

occurring and determined the sequence of physiological and morphological changes in the four RGC types. We then compared the progression of morphological and functional changes of the RGCs to ascertain whether or not perturbations occurred concurrently across RGC types. Together, our findings raise the possibility that RGCs may lose synaptic drive before gross changes to their structure and underscore the fact that diverse RGC types respond to IOP elevation at different time-scales and to varying extents.

\section{Materials and Methods}

Animals. The transgenic mouse line B6.Cg$\mathrm{Tg}(\mathrm{Thy} 1-Y F P H) 2 J r s / J$, in which individual RGC express YFP, was obtained from Jackson Laboratory and bred in our local mouse facility. Mice aged $30 \mathrm{~d}$ of either sex were used for experiments. All procedures were performed in accordance with the University of Washington Institutional Animal Care and Use Committee protocols.

Microbead injection. Mice were anesthetized (Avertin, $1.3 \%$ tribromoethanol $+0.8 \%$ tertamyl alcohol) and IOP measured for each eye using the Tonolab rebound tonometer (Colonial Medical Supply). Each IOP measurement is the average of 10 repetitions. For microbeads injection into the eye, mice were placed under a surgical scope and a glass-pulled pipette fitted to a microinjection system (Narishige) was brought to a point just temporal to the central cornea. Using Graefe forceps (Roboz) to support the eye, the glass-pulled pipette containing $10 \mu \mathrm{m}$ polystyrene microspheres (FluoSpheres, Invitrogen) was used to penetrate the cornea and then to inject $1 \mu \mathrm{l}$ of microspheres into the anterior chamber. A small amount of air was also injected to ensure no efflux of the microspheres. The same method was used in the contralateral eye with saline injection in lieu of microspheres, to serve as a control. Occasionally, the injection procedure led to blood clots or the cornea became opaque; these animals were not used for the present study. IOP was monitored weekly and mice that showed a transient or normal IOP were not included here. Three of 19 injected mice were therefore excluded from the study. We did not expect major changes in blood flow to be a factor within the duration of IOP elevation (15-30 d) because the IOP elevation was modest, compared with the blood pressure of the animal (Mattson, 2001). However, we cannot exclude that alteration in blood flow might become relevant in the long term.

Spatial frequency threshold measurement. Spatial frequency threshold (SFT; cycles/degree) was determined using the OptoMotry system for tracking optokinetic response (Prusky et al., 2004). The temporal-nasal dominance of the op-

Correlation between IOP elevation and cell loss for each animal. For all plots $(\boldsymbol{A}-\boldsymbol{F})$, each symbol represents the salineand bead-injected eyes from an individual animal. 
A

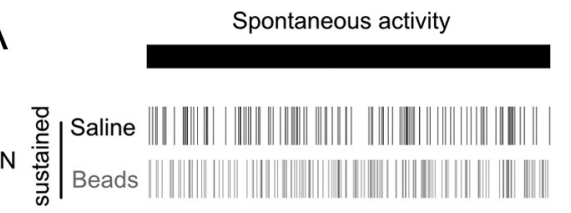

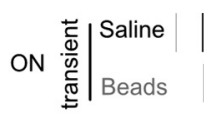

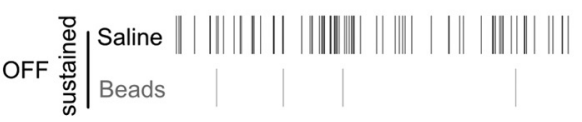

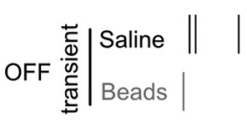

ON-OFF $\mid \begin{aligned} & \text { Saline } \\ & \text { Beads }\end{aligned}$

C
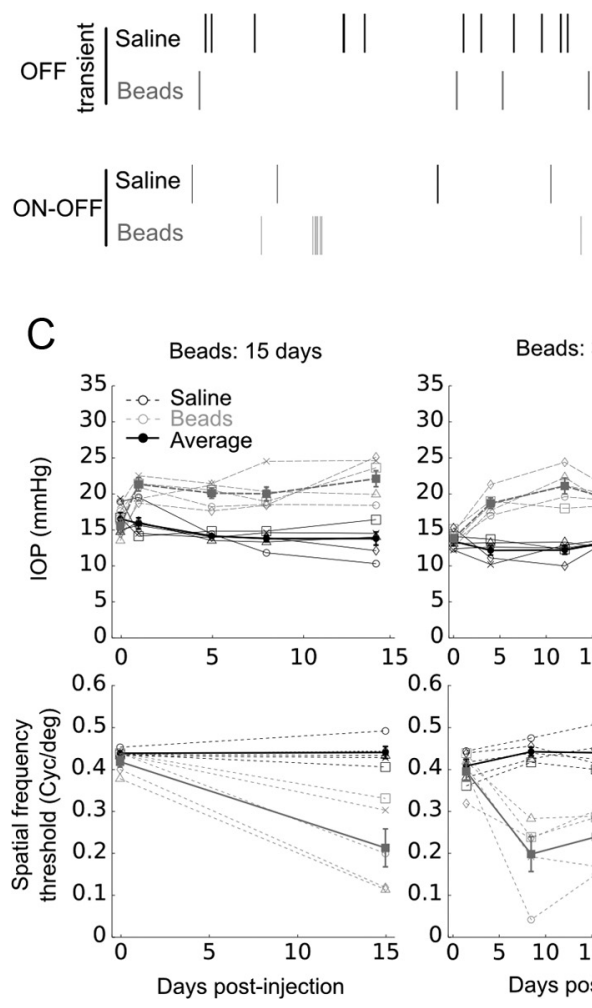
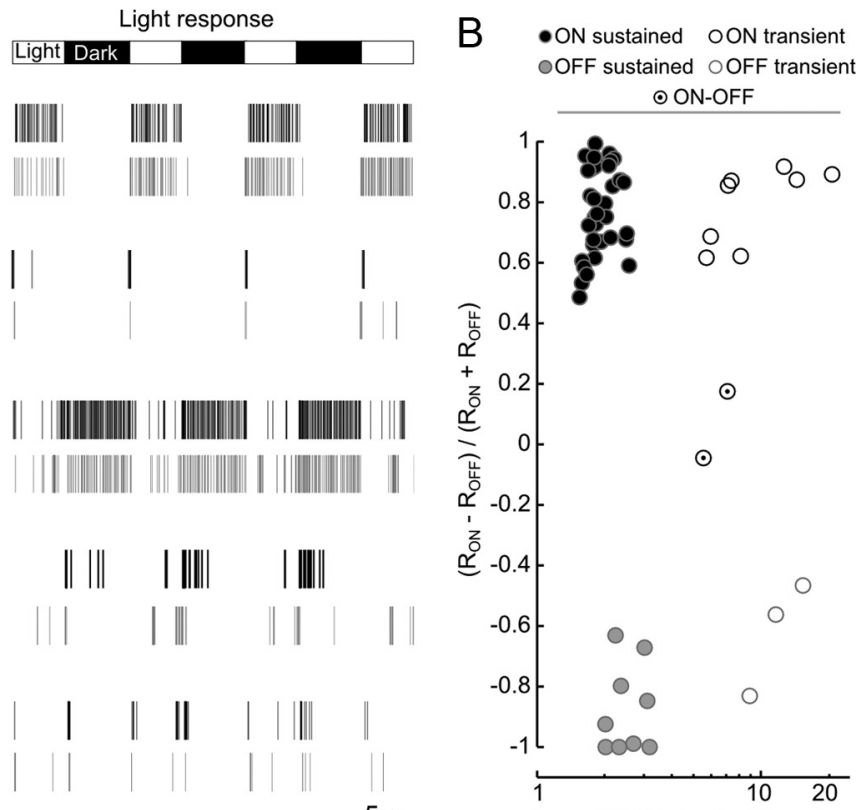

$5 \mathrm{~s}$
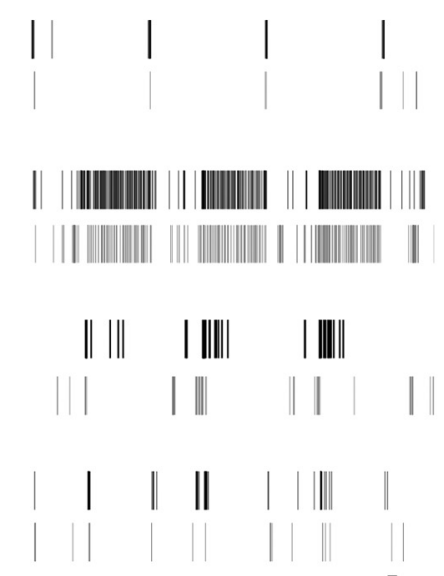

$\mathrm{D}$
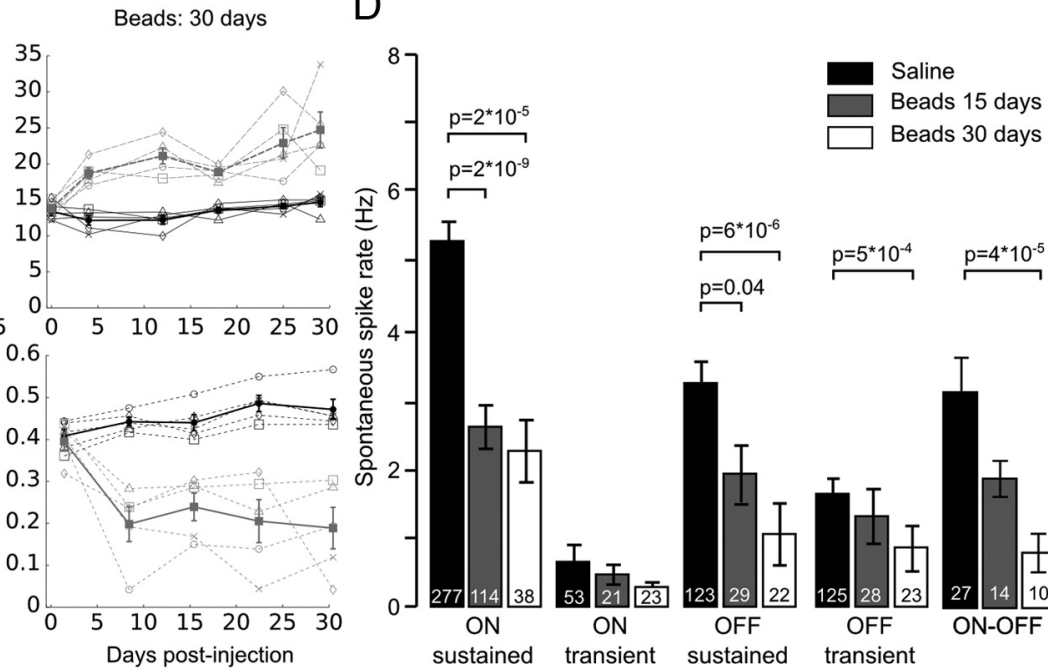

Figure 2. Spontaneous activity of RGCS is reduced following IOP elevation. $A$, Spike raster plots of representative RGCs showing spontaneous activity and their responses to square-wave full-field light stimulation (4s ON, 5s OFF). Shown here are RGCs recorded from saline-injected (blacklines) or microbead-injected eyes (gray lines), 30 dafter injection. $\boldsymbol{B}$, Five major types of RGCs were identified based on their response profiles to light $0 \mathrm{~N}$ and $0 \mathrm{FF}$, shown here for one recording. $R_{0 \mathrm{~N}}$ and $R_{\text {OFF }}$ are the average spike rate in response to light $0 \mathrm{~N}$ or $0 \mathrm{FF}$, respectively. $y$-axis: Values closer to 1 indicate $0 \mathrm{~N} R \mathrm{RGCs}$; values closer to -1 indicate $0 \mathrm{FF}$ RGSS, values close to zero indicate $\mathrm{ON}-0 \mathrm{FF}$ RGCS. $x$-axis: Values approaching 1.0 indicate relatively sustained responses. See Materials and Methods for definition of these parameters. C, Plots of IOP and SFT for mice recorded 15 or $30 \mathrm{~d}$ after injection ( $n=5$ animals each). $\boldsymbol{D}$, Quantification of the average spontaneous spike rates of each major RGC type for the animals whose IOPs and SFTs are shown in C. Numbers inside histograms represent number of recorded cells. Statistics: Wilcoxon-Mann-Whitney rank sum test.

tokinetic response in rodents allowed the SFT to be determined for each eye by switching between the directions of travel of a vertical sine wave grating. Mice were placed on a platform centered among four LCD screens on which a vertical sine wave grating traveled in either a clockwise or counterclockwise direction. The SFT was obtained for both eyes (bead or saline-injected) of an animal.

Multielectrode array recording. Mice reared in a normal $12 \mathrm{~h}$ light/dark environment were dark-adapted $2-3 \mathrm{~h}$ before the experiment, then killed by cervical dislocation. Eyes were removed under dim red light and corneas punctured with a 30 gauge needle, before being transferred to oxygenated artificial CSF (ACSF) solution for dissection, containing the following (in $\mathrm{mm}): 130 \mathrm{NaCl}, 2.5 \mathrm{KCl}, 1 \mathrm{MgCl}_{2}{ }^{\star} 6 \mathrm{H}_{2} \mathrm{O}, 2 \mathrm{CaCl}_{2}{ }^{\star} 2 \mathrm{H} 2 \mathrm{O}, 1.25 \mathrm{NaHPO}_{4}, 20$ glucose, $21 \mathrm{NaHCO}_{3}$. All the following procedures were performed in a completely darkened room under infrared illumination using microscopemounted infrared converters (B. E. Meyers). The cornea, lens and vitreous were carefully removed and retina dissected free from eyecup. Dissected retinas were hemisected and a $4-9 \mathrm{~mm}^{2}$ rectangle was obtained after trimming away the central and far peripheral portion of the piece.

The multielectrode arrays (Multi-Channel Systems) used have 60 electrodes arranged in an $8 \times 8$ square grid without electrodes at the four corners. Electrodes of $10 \mu \mathrm{m}$ in diameter were spaced either 200 or $100 \mu \mathrm{m}$ apart. The retina was transferred to the array chamber and oriented ganglion cell side down, with the central portion of the piece in contact with the electrodes. The retina was covered by a $25-50 \mathrm{~mm}^{2}$ square piece of tissue culture membrane (Corning Life Sciences), held in place by a platinum ring, and the chamber filled with ACSF. Tissue was superfused continuously with oxygenated ACSF at a rate of $2.5 \mathrm{ml} / \mathrm{min}$. The temperature of the bath was maintained at $31-33^{\circ} \mathrm{C}$ (the probe was placed near the retina) by heating the bottom of the recording chamber and the incoming solution. Retinas were left on the array for at least $30 \mathrm{~min}$ before recording, because the amplitude of the recorded spikes usually improved during this period. Most recordings lasted $1-2 \mathrm{~h}$. 
A
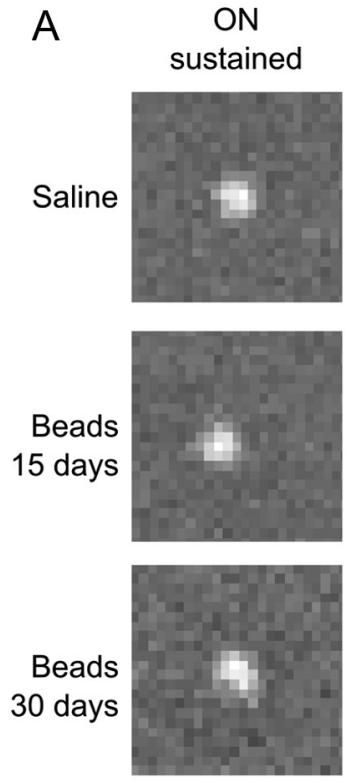

B

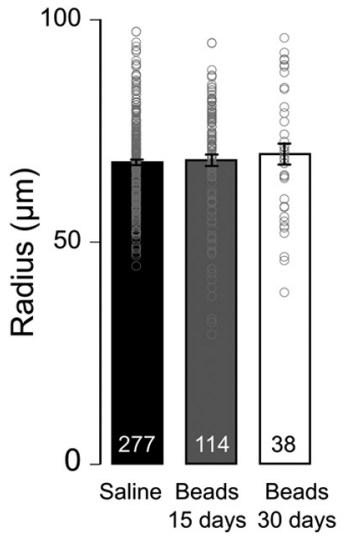

ON transient
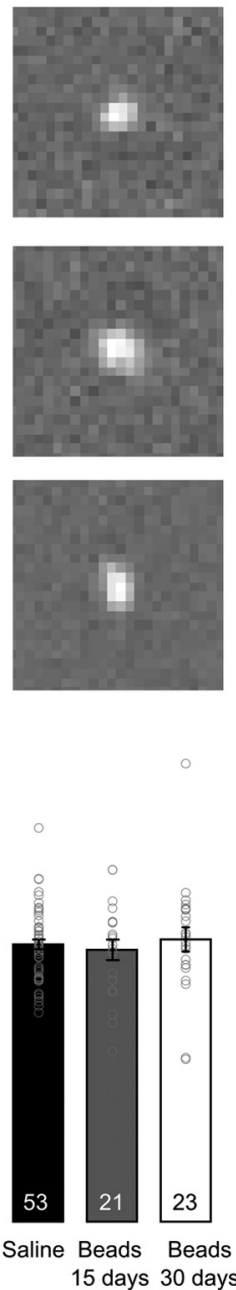
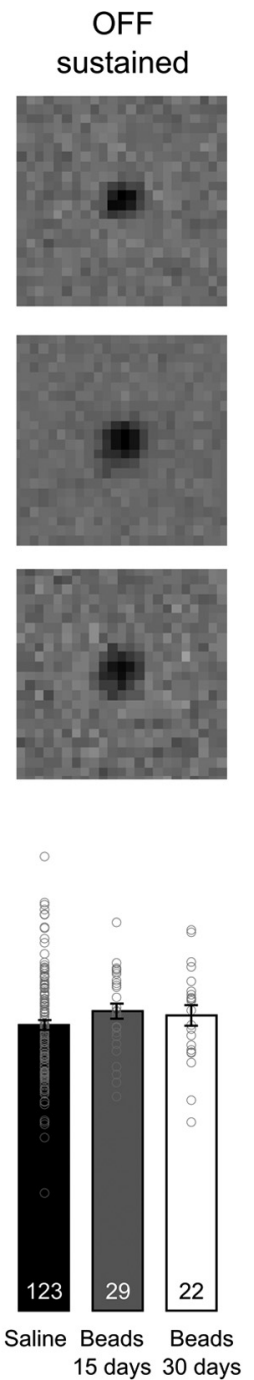

Figure 3. OFF transient RGCS rapidly demonstrate altered receptive field center size after IOP elevation. $\boldsymbol{A}$, Spatial representations of the preferred stimuli for representative RGCs in saline- or microbead-injected eyes. Each image is the average stimulus taken at the maximum (for ON RGCS) or minimum (for OFF RGCS) of the STA temporal profile, during checkerboard Gaussian white noise stimulation. B, Quantification of the average receptive field center size of the cells in Figure 2 revealed a significant reduction only for OFF-transient RGCs after microbead injection. Numbers in histograms indicate number of cells recorded; 5 mice per group. Statistics: Wilcoxon-Mann-Whitney rank sum test.

Signals were bandpass filtered between 100 and $3000 \mathrm{~Hz}$, and digitized at a rate of $20 \mathrm{kHz}$. Thresholds above baseline noise levels were set to five times above SD of noise level and, if needed, manually adjusted. In general, RGC somatic spikes were biphasic, with a larger initial negative phase; therefore, negative triggers were used in every case. Only spike cutouts, comprising $1 \mathrm{~ms}$ before and $2 \mathrm{~ms}$ after a trigger event, along with a time stamp of the event were saved. After recording, the position of the tissue on the array was verified on the dissecting microscope and a bright field image recorded with a digital camera (Sony).

Visual stimulation. Stimuli were presented on a monochrome white organic light emitting diode display (OLED; eMagin Corporation; mean luminance at the retina $\sim 10^{5}$ photoisomerizations per middlewavelength-sensitive cone per second; resolution, $800 \times 600$ pixels; 75 $\mathrm{Hz}$ vertical refresh rate) illuminating the back focal plane of a $10 \times \mathrm{ob}-$ jective (UPlanFL N; Olympus) mounted on an inverted microscope (Axiovert S 100; Zeiss) in place of the condenser and focused on the photoreceptors of the retina. Stimuli were programmed in Matlab (MathWorks) using the Cogent graphics toolbox extensions (Wellcome Laboratory of Neurobiology, University College London, London, UK). Full-field square wave and checkerboard Gaussian white-noise stimuli were presented. For checkerboard stimuli, the intensity of squares $(51 \mu \mathrm{m}$ side

OFF transient
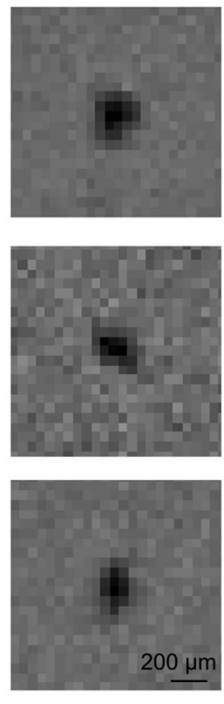

$\mathrm{p}=0.0002$ $\mathrm{p}=0.0002$

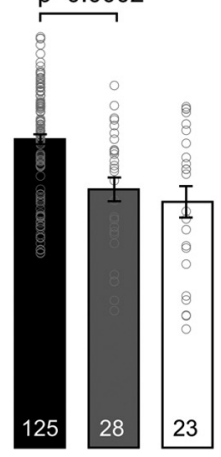

Saline Beads Beads 15 days 30 days length) on the retina was randomly chosen from a Gaussian distribution with constant mean and SD every $40 \mathrm{~ms}$ (effective refresh rate, $25 \mathrm{~Hz}$ ). Full-field square wave stimuli were delivered as $100 \%$ contrast steps, 4 s ON, 5 s OFF, 15 repetitions.

Spike sorting and data analysis. Typically, spike cutouts from more than one cell were recorded on a single electrode. For each electrode, these spike cutouts were sorted into single cell trains after recording using Offline Sorter (Plexon) as reported previously (Tian and Copenhagen, 2001; Demas et al., 2003; Kerschensteiner et al., 2008). The quality of the spike sorting was controlled by verifying refractory periods of the sorted trains. Only cells with $<0.2 \%$ interspike intervals smaller than 2 $\mathrm{ms}$ were used for analysis. Data analysis and display were performed using custom software written in Matlab (MathWorks).

To manually cluster cells into functional types, the following parameters were quantified from responses to full-field square wave light stimulation. Preference to $\mathrm{ON}$ or $\mathrm{OFF}$ light steps was quantified as follows:

$$
\frac{R_{\mathrm{ON}}-R_{\mathrm{OFF}}}{R_{\mathrm{ON}}+R_{\mathrm{OFF}}}
$$

where $R_{\mathrm{ON}}$ and $R_{\mathrm{OFF}}$ are, respectively, the average spike rate during ON or OFF steps of light, corrected by the basal spiking rate in darkness. This parameter can assume values between 1 and -1 , where 1 represents a cell spiking only during ON steps, and -1 represents a cell spiking only during OFF steps.

Transiency of the response to a step of light was quantified as follows:

$$
R_{\text {peak }} / R_{\text {maintained }},
$$

where $R_{\text {peak }}$ is the peak firing rate in the first $500 \mathrm{~ms}$ after light onset/offset, and $R_{\text {maintained }}$ is the average firing rate from $1 \mathrm{~s}$ after light onset/ offset to the end of the step.

Spontaneous spike rate was quantified for each neuron as the average spike rate during 5 min of recording before light stimulation. Light responses of RGCs were described using a linear-nonlinear (LN) cascade model (Chichilnisky, 2001). Briefly, the first and linear stage of the LN model consists of a set of filters describing the spatial and temporal sensitivity profile of the cell, which are equivalent to its space-time receptive field. The stimulus is convolved with these filters, and the second stage of the model then describes how the filtered stimulus is transformed into the spiking response of RGCs. The linear stage was retrieved by correlating the stimulus to the response to compute the spike-triggered average (STA) stimulus. For checkerboard stimulation, we isolated the spatial and temporal aspects of the receptive field as follows. At the temporal maximum of the STA, a general two-dimensional Gaussian was fit to the spatial response profile. Similar to recordings from other species using comparable stimulation conditions (Devries and Baylor, 1997; Segev et al., 2006), receptive field surrounds were weak in our recordings, and fitting receptive field profiles with a difference of Gaussians offered no significant improvement and was therefore not included in the present analysis. The radius of the receptive field $(r)$ was defined as follows:

$$
r=\sqrt{r_{\text {min }} \cdot r_{\text {maj }}}
$$

where $r_{\min }$ and $r_{\text {maj }}$ are the radii along the minor and major axis respectively, of the $1 \mathrm{SD}$ ellipse from Gaussian fits. 

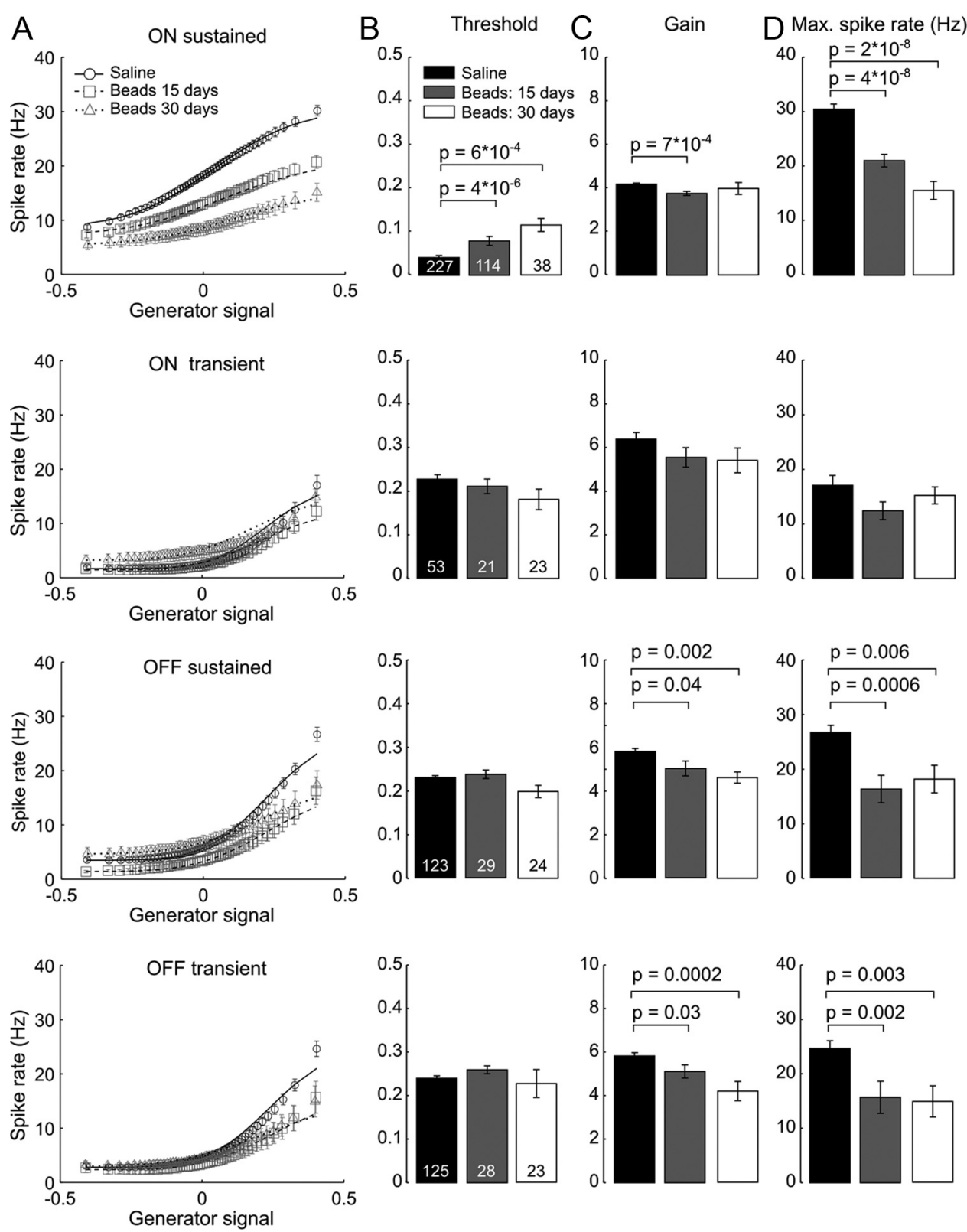

Figure 4. Nonlinearities in the light responses are differentially affected among RGC types. $A$, Average spike rates as a function of the generator signal. Cumulative distribution functions were fitted (lines) to the experimental data points. $\boldsymbol{B}-\boldsymbol{D}$, Average values of threshold $(\boldsymbol{B})$, gain $(\boldsymbol{C}$, and maximal spike rate $(\boldsymbol{D})$ are differentially affected among the RGC types. See Materials and Methods for the definition of these parameters. Cell numbers are noted in the histograms; 5 animals per group. Statistics: by Wilcoxon-Mann-Whitney rank sum test.

The generator signal was calculated by convolving the stimulus with the STA. To avoid biasing LN model estimation, STA and generator signal were computed from separate parts of the recording. We assessed the dependence of the spike rate on the filtered stimulus by averaging the spike rate during time bins with similar generator signal values and used a standard normal cumulative distribution function (cdf) (Chichilnisky, 2001) to describe the average spike rate as a function of the generator signal according to:

$$
f_{(x)}=\alpha C(\beta(x-\gamma)),
$$

where $f_{(x)}$ is the average spike rate, $x$ is the generator signal, $C(\ldots)$ is the cdf, $\alpha$ is the maximum firing rate of the cell, $\beta$ is the response gain, and $\gamma$ is the spike threshold. We used a Gauss-Newton algorithm with modifications for global convergence to find least-squares parameter estimates.

Because parameters measured in saline-injected control eyes showed no statistically significant difference between animals recorded at 15 or
$30 \mathrm{~d}$ after injection, control data from the two ages were pooled together. Statistical significance was obtained using Wilcoxon-Mann-Whitney rank sum test unless otherwise specified. Results are expressed as mean value \pm SEM.

Biolistic transfection. Mice were killed by cervical dislocation. Eyes were removed and placed in HEPES-buffered mouse ACSF containing the following (in $\mathrm{mm}$ ): $\mathrm{NaCl}$ (119), $\mathrm{KCl}(2.5), \mathrm{MgCl}_{2}$ (1.3), $\mathrm{CaCl}_{2}$ (2.5), $\mathrm{NaHPO}_{4}$ (1), glucose (11), HEPES (20), pH 7.4. Retinas were isolated from the eyecup under a dissection microscope and mounted onto nitrocellulose filter paper (Millipore). DNA-coated gold particles were prepared by coating $12.5 \mathrm{mg}$ of $1.6 \mu \mathrm{m}$ gold particles (Bio-Rad) with $20 \mu \mathrm{g}$ of $C M V$ :tdTomato and $7 \mu \mathrm{g}$ of PSD95-CFP plasmids. A Helios gene gun (Bio-Rad) was used to ballistically deliver plasmid-coated gold particles to whole-mounted retinas. A suspension of DNA-coated gold particles in ethanol was precipitated onto the inner surface of Teflon tubing (BioRad), subsequently cut into short segments ( $12 \mathrm{~mm}$ long). Gold particles were propelled onto the tissue using helium gas at 40 psi. Retinas were 
Table 1. Correlation between magnitude of IOP increase and functional responses of RGCs

\begin{tabular}{|c|c|c|c|c|}
\hline Group and parameter & ON sustained & ON transient & OFF sustained & OFF transient \\
\hline \multicolumn{5}{|l|}{ Beads: $15 \mathrm{~d}$} \\
\hline IOP versus RF size & 0.0073 & $2.6^{*} 10^{-5}$ & 0.071 & 0.1346 \\
\hline IOP versus spontaneous rate & 0.0354 & $5.8^{*} 10^{-6}$ & 0.0152 & 0.0259 \\
\hline IOP versus maximum firing rate & 0.0803 & 0.0068 & 0.0817 & 0.1215 \\
\hline IOP versus gain & 0.0562 & 0.0201 & 0.15 & 0.1257 \\
\hline IOP versus threshold & $6^{*} 10^{-4}$ & $1.6^{*} 10^{-4}$ & 0.0022 & 0.0288 \\
\hline \multicolumn{5}{|l|}{ Beads: $30 \mathrm{~d}$} \\
\hline IOP versus RF size & 0.0169 & 0.0253 & $2 * 10^{-7}$ & 0.1486 \\
\hline IOP versus spontaneous rate & 0.1064 & 0.0035 & 0.0619 & 0.0488 \\
\hline IOP versus maximum firing rate & 0.0747 & 0.0035 & 0.0218 & 0.0974 \\
\hline IOP versus gain & 0.1563 & 0.0488 & 0.0034 & 0.2194 \\
\hline IOP versus threshold & 0.1212 & 0.1157 & 0.0024 & 0.0738 \\
\hline
\end{tabular}

Correlation coefficients ( $R^{2}$ values) of the linear regression fits to plots of the functional parameters measured in the $\mathrm{RGCS}$, against the average IOP increase in the eye. There is no systematic relationship between the magnitude of the functional change and the amount of IOP elevation for cells represented in Figures 2, 3, and 4.
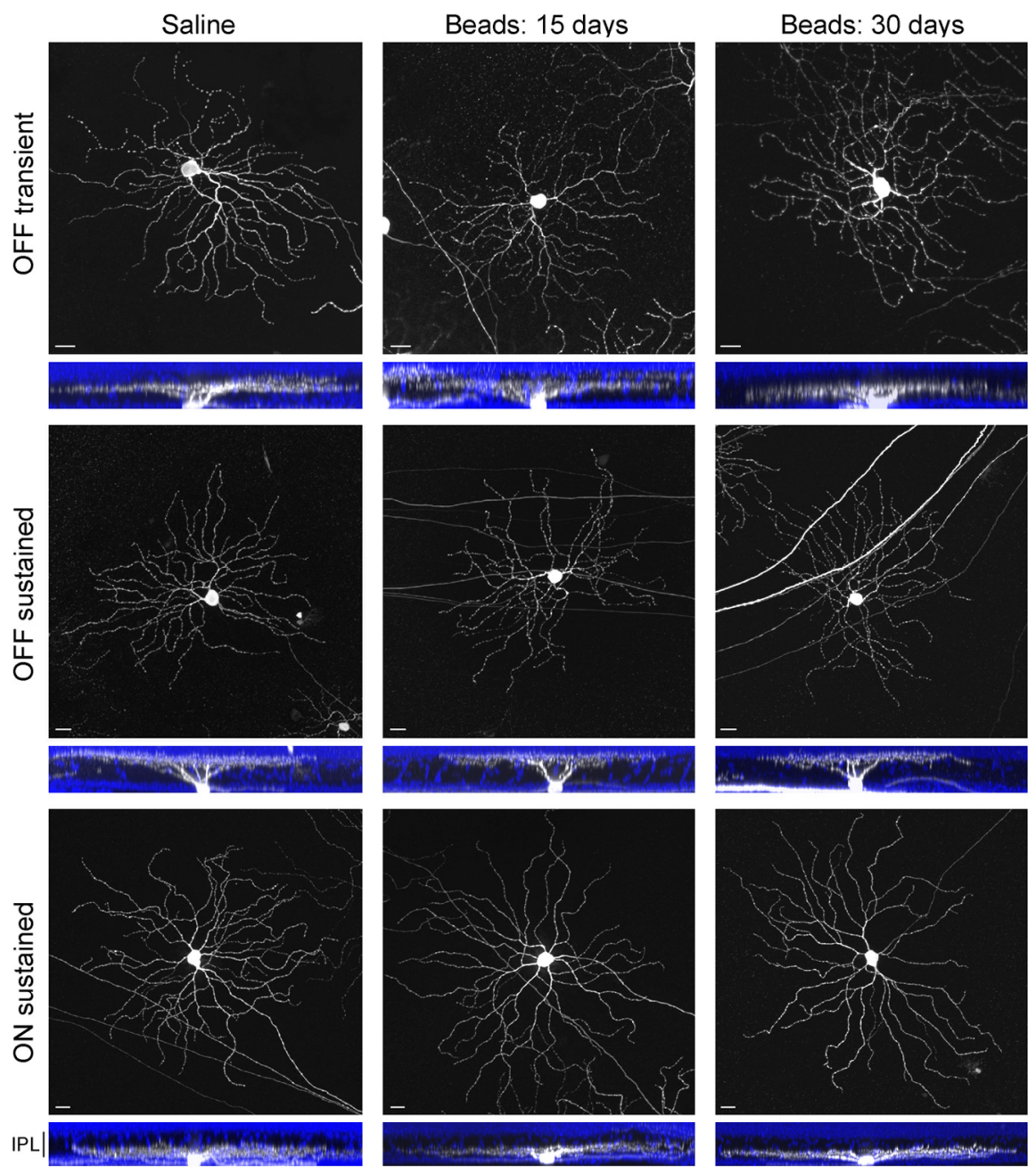

Figure 5. Dendritic arbor of three RGC types in control and microbead-injected eyes. Maximum intensity projections of confocal image stacks of RGCs in Thy1-YFP retinas from recorded saline-injected and microbead-injected mice. Orthogonal rotations of the arbors are provided below the $x-y$ views. Blue labeling represents staining of cell nuclei in the ganglion cell layer and inner nuclear layer with T0-PR03. Scale bars, $20 \mu \mathrm{m}$. IPL, Inner plexiform layer.

then transferred to an oxygenated and humidified chamber and maintained for $29 \mathrm{~h}$ at $32^{\circ} \mathrm{C}$, allowing fluorescent protein to be expressed sufficiently for subsequent imaging.

Immunohistochemistry. Retinas were fixed in 4\% paraformaldehyde in $\operatorname{ACSF}(\mathrm{pH}=7.4)$ for $15-30 \mathrm{~min}$. After fixation, retinas were rinsed in 0.1
M PBS. Retinas were processed for immunostaining as follows: blocked in $5 \%$ normal goat serum (NGS) in PBS overnight at $4^{\circ} \mathrm{C}$ followed by $5 \mathrm{~d}$ incubation in 5\% NGS, $0.5 \%$ Triton X-100, with the corresponding primary antibodies. The primary antibodies used were a mouse monoclonal anti-PSD95 antibody (1:1000; Abcam), a rabbit polyclonal anti-GFP (1: 1000; Invitrogen), and a goat anti-Brn3a antibody (1:200; Santa Cruz Biotechnology). Flat mounts were then washed $3 \times 10 \mathrm{~min}$ in PBS and incubated overnight at $4^{\circ} \mathrm{C}$ with the corresponding secondary antibodies, conjugated to either Alexa-568 (1:1000; Invitrogen) or Dy-light 488 or Dy-light 649 (1:1000; Jackson ImmunoResearch Laboratories). Cell nuclei were stained applying TO-PRO 3 iodide for $30 \mathrm{~min}$ (1:2000; Invitrogen). Retinas were then washed $3 \times 10 \mathrm{~min}$ in PBS and mounted onto glass slides using Vectashield (Vector).

Image acquisition and analysis. Confocal images were acquired using a FV 1000 microscope (Olympus) equipped with either a 1.35 NA $60 \times$ oil objective or a 0.8 NA $20 \times$ oil objective (Olympus). To measure dendritic arbor parameters, dendrites of individual RGCs were skeletonized using Simple Neurite Tracer (Longair et al., 2011). Dendritic arbor parameters of each cell were measured from a two-dimensional projection of the dendritic skeleton on the $x-y$ plane using custom-written Matlab routines (MathWorks). Dendritic territory was defined as the area of the convex hull enclosing the dendritic arbor. Total dendritic length was quantified as the sum of the length of all the dendritic segments. The total number of dendrites was determined as the total number of dendritic segments present in the skeleton. YFP-expressing cells were imaged from retinal pieces after multielectrode recording, and also from nonrecorded portions of the same retinas.

Cell density in the ganglion cell layer was obtained by manually counting cells labeled by TO-PRO3 and anti-Brn3a within an area of $45,000 \mu \mathrm{m}^{2}$. Cell counts were performed on the maximum intensity projections using ImageJ (Schneider et al., 2012). Within each retinal quadrant, three different locations were sampled from the inner, middle, and outer third of the retina from the optic nerve head. Cell density was expressed as the average number of cells per square millimeter, pooled for each quadrant.

To determine PSD95-CFP puncta distributions on RGC dendrites, image stacks were acquired at $0.103 \times 0.103 \times 0.3 \mu \mathrm{m}$. Retinas biolistically transfected for investigating dendritic morphology (see Figs. 7, 8) were subsequently used for assessing cell death (Fig. 1). Retinas recorded with multielectrode array were immunolabeled for PSD95 (see Fig. 9). Dendritic stratification patterns were visualized relative to the position of the ganglion cell and inner nuclear layers defined by TO-PRO3 labeling. We used a semiautomated method previously described (Morgan et al., 2008), with some modifications, to identify PSD95CFP puncta. Images were preprocessed by median-filtering using a $3 \times 3$ kernel, which removed the thermal noise of the microscope's photomultipliers. Using Imaris 6.3 (Bitplane), YFP or tdTomato fluorescence in the cell was used to create a three-dimensional skeleton of the dendritic tree. Custom-written Matlab routines then created a binary mask of the dendritic tree from the skeleton, which was then used to include PSD95-CFP or immunolabeled PSD95 signal only within the dendrites. Candidate puncta were identified using an iterated threshold method, and selected based on differences in local contrast between the puncta and the back- 
A

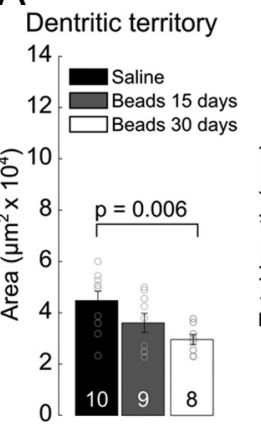

C

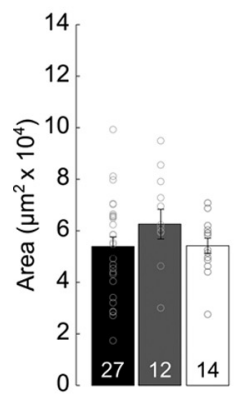

$\mathrm{E}$

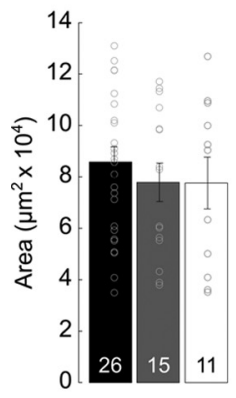

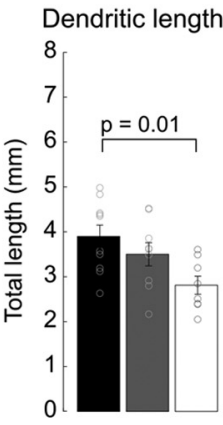

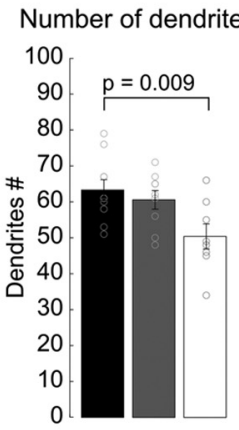

B

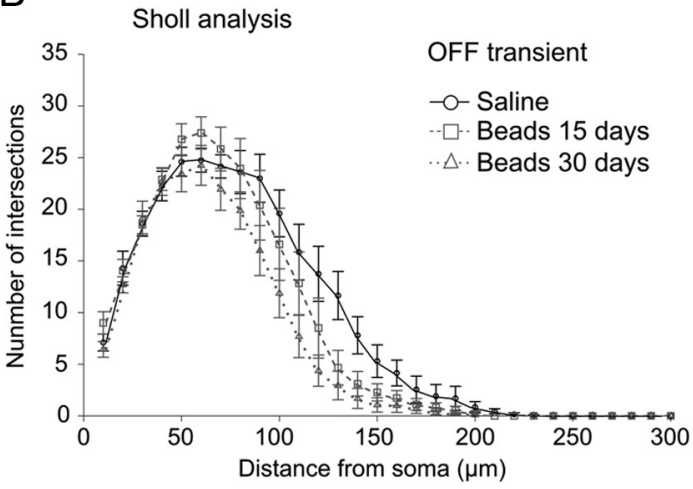

D
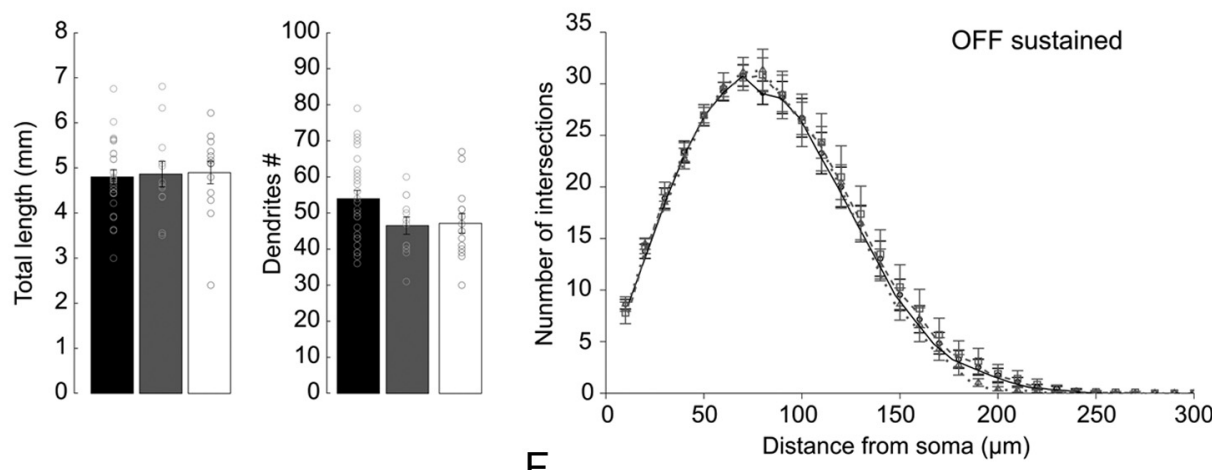

$\mathrm{F}$
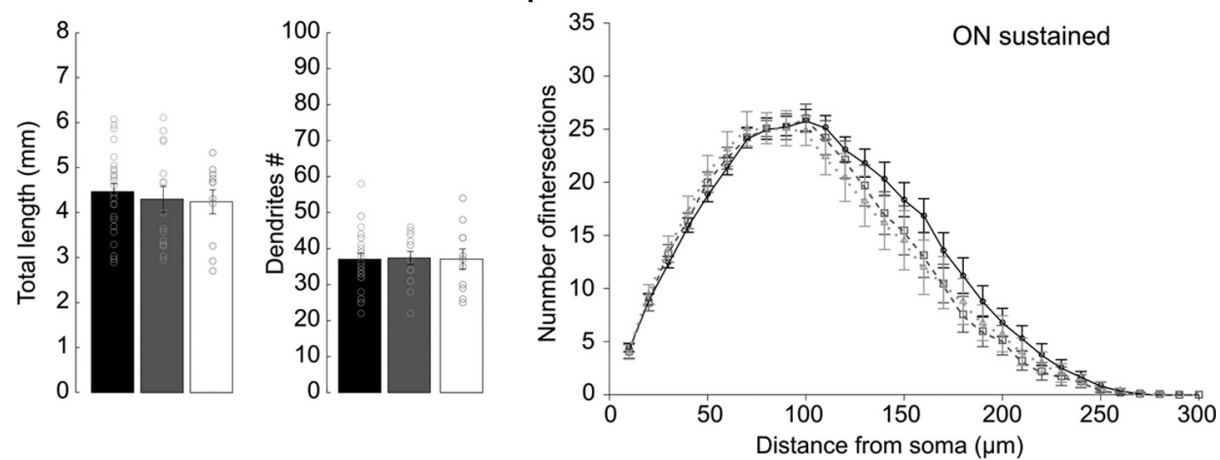

Figure 6. Reduction in receptive field size of OFF-transient RGCs occur before pronounced dendritic changes. $A-F$, Measurements of dendritic territory, total dendritic length, and number of dendrites $(\boldsymbol{A})$ and Sholl analysis for OFF-transient RGCS $(\boldsymbol{B})$, OFF-sustained RGCS $(\boldsymbol{C}, \boldsymbol{D})$, and for ON-sustained RGCS $(\boldsymbol{E}, \boldsymbol{F})$ in control saline and bead conditions. These measurements were performed on RGCs labeled in retinas from Thy1-YFP mice after multielectrode array recording. See Materials and Methods for definitions of the morphological measurements. Cell numbers are noted in the histograms; 5 animals per group. Statistics: Wilcoxon-Mann-Whitney rank sum test.

ground within the mask (Morgan et al., 2008). Candidate puncta present in only one confocal plane or smaller than $0.25 \mu \mathrm{m}$ in diameter were rejected. A final validation of all selected puncta was performed by simultaneously viewing the selected puncta and the raw puncta signal in three-dimension, using Imaris. The average linear density of puncta was obtained by dividing the total number of puncta by the total length of the dendritic tree. Linear density of puncta as a function of distance from the cell soma was attained by calculating the density of puncta along the dendritic skeleton of dendrites within a moving window of $10 \mu \mathrm{m}$.

\section{Results}

IOP elevation induces cell death in the ganglion cell layer

For each eye, we directly compared IOP elevation with the extent of cell death in the ganglion cell layer with the SFT of the OptoMotry test. Injection of polystyrene microbeads into the anterior chamber of the mouse eye at the age of P30 caused a sustained elevation of IOP (Fig. 1A). In contrast, IOP remained normal in the contralateral eye that received an injection of saline solution
(Fig. 1A). A significant increase in IOP was detected and persisted for at least $30 \mathrm{~d}$ ( $p=0.00005$, ANOVA one-way). OptoMotry analysis demonstrated that eyes injected with microbeads already showed significant impairment in visual behavior $3 \mathrm{~d}$ after the injection (Fig. $1 B, p=0.002$ ). This visual performance remained significantly lower compared with saline-injected control eyes up to $30 \mathrm{~d}$ (Fig. $1 B, p=0.002$ ). Control eyes maintained normal optokinetic performance after saline injection.

A progressive reduction of cells in the ganglion cell layer after IOP elevation was revealed by colabeling of the retinas with the nuclear dye, TO-PRO3, and with the ganglion cell marker, Brn3a (NadalNicolás et al., 2009) (Fig. 1C). There was an average of $24.2 \pm 0.6 \%$

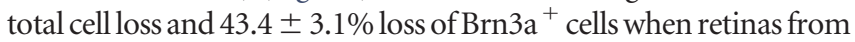
microbead eyes were compared with saline-injected control eyes. The average cell density of the control eyes was comparable to the previously reported density of cells in the mouse ganglion cell layer (Jeon et al., 1998). Cell loss was not restricted to a specific location of the retina 

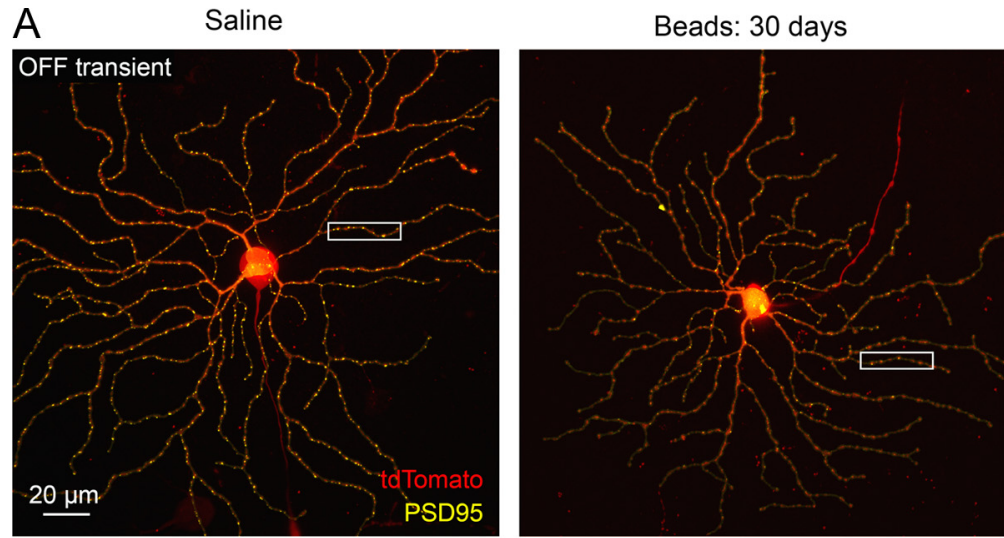

$\mathrm{B}$
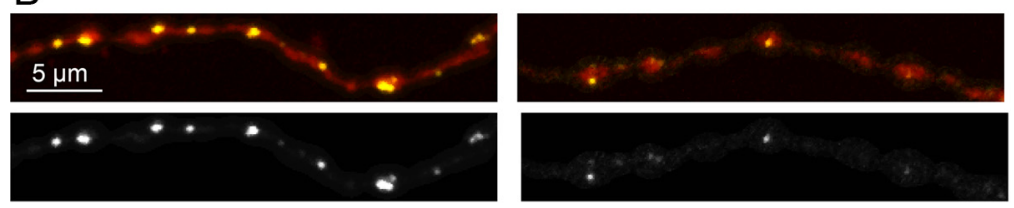

C
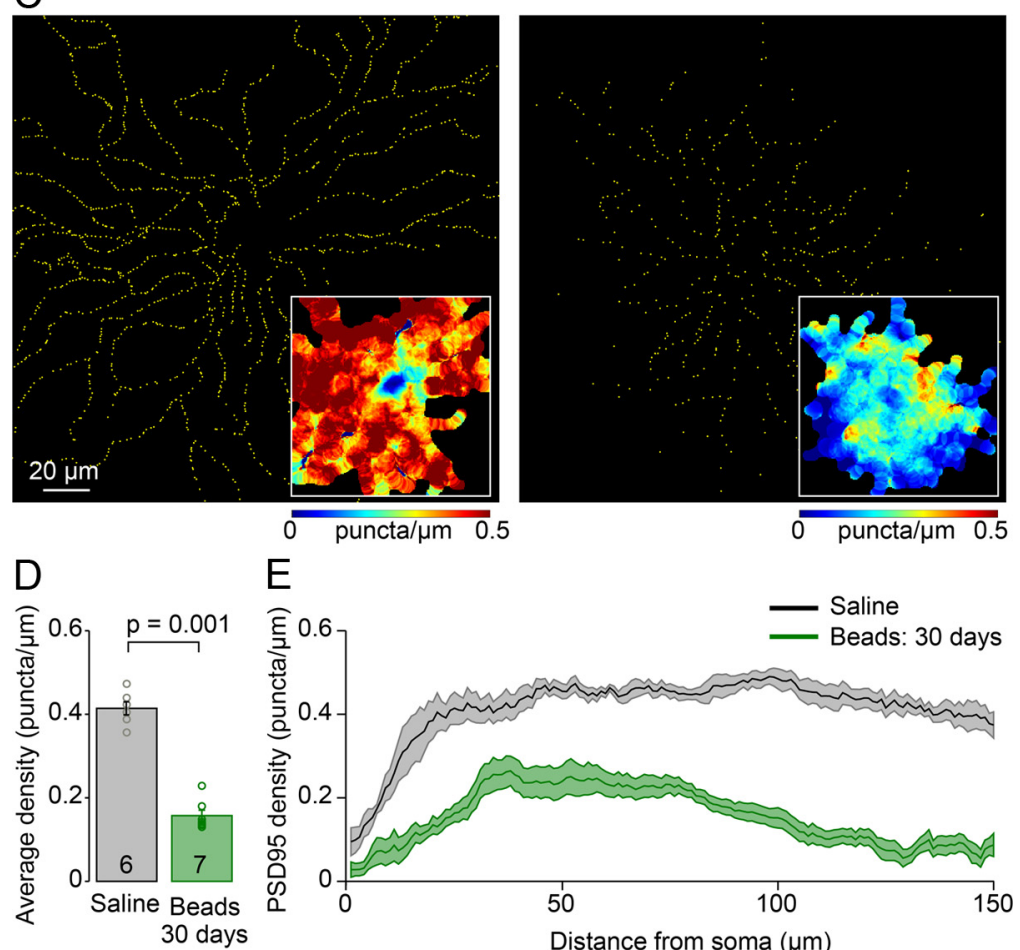

$\mathrm{E}$
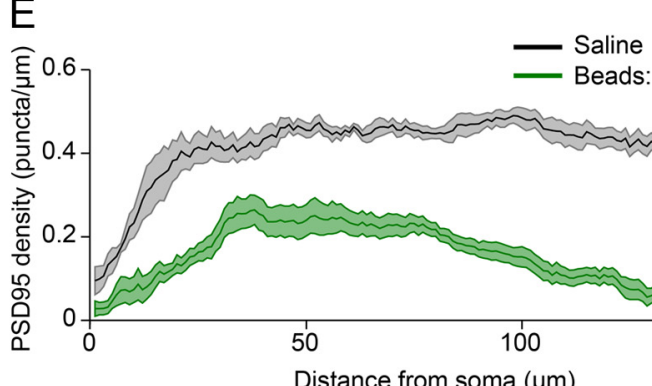

Figure 7. OFF transient RGCS show decreased synaptic density in addition to reduced dendritic arborization. $\boldsymbol{A}$, Example of biolistically labeled OFF transient-RGCs in control and microbead-injected eyes. Cells coexpressed PSD95-CFP and tdTomato. $\boldsymbol{B}$, Magnified views of the dendrites within the boxed area in $\boldsymbol{A}$. C, Distribution of identified PSD95-CFP puncta of the cells in $\boldsymbol{A}$, represented by yellow dots. Insets show "heat-maps" of the linear density of PSD95 of the cell. Hotter colors indicate higher density of PSD95 puncta (Morgan et al., 2008). D, Average linear density of PSD95 puncta across conditions, from retinas of animals in Figure 1. Cell numbers are provided in the histograms ( $n=5$ mice each condition). Statistics: Wilcoxon-Mann-Whitney rank sum test. $\boldsymbol{E}$, Average linear density of PSD95 puncta as a function of distance from the soma position. Solid line: average value of sampled cells; colored band: SEM.

(Fig. $1 D)$ and was not greater in any one quadrant $(p=0.85$ for TOPRO3 cell count, $p=0.82$ for Brn3a + cells, ANOVA one-way).

The degree of visual deficit, as measured by the optokinetic response, was strongly correlated to the amount of IOP elevation (Fig. $1 E, R^{2}=0.66$ ). However, the extent of cell death was not correlated to IOP elevation (Fig. $1 F, R^{2}=0.11$ ), within the range of IOP increase (5-12 $\mathrm{mmHg}$ ) of the microbead-injected eyes.
Comparisons of all three parameters for each eye thus revealed that loss in visual performance is not only due to cell death, but likely also reflects progressive alterations in retinal function before death.

Spontaneous activity of ganglion cells is reduced after IOP elevation

We recorded the spike activity of RGCs in animals with sustained IOP elevation and decreased optokinetic performance. Multielectrode array recordings enabled us to record simultaneously from many RGCs, and also directly compare the spiking activity and light-responses of neighboring cells within a local region of the retina. To compare the activity of remaining RGCs of the same physiological type, we classified the RGCs based on their response to a square-wave stimulus (Fig. $2 A$ ), rather than on properties of the linear filter (Kerschensteiner et al., 2008). ON and OFF RGCs were grouped based on whether their average spike rate increased or decreased upon light onset. RGCs were then further subgrouped according to sustained or transient responses. When we clustered the cells according to both methods, we did not find a strict one-to-one correspondence between subtypes of ON and OFF RGCs; for example, within ON-responding clusters, "fast versus slow" responders (linear filter classification) are not necessarily "transient versus sustained" cells (square-wave classification). We chose here to use the classification scheme based on the square-wave stimulus so that our results can be compared with mouse RGC types previously identified by structure-function analyses using single-cell recording methods (Pang et al., 2003; Murphy and Rieke, 2006; van Wyk et al., 2009; Margolis and Detwiler, 2011). From these criteria, we obtained five major types, as shown in Figure $2 B$ for an example recording: $\mathrm{ON}$ sustained, $\mathrm{ON}$ transient, OFF sustained, OFF transient, $\mathrm{ON}-$ OFF. These five RGC types accounted for $\sim 85 \%$ of the recorded neurons. The remaining cells had no detectable light response $(n=1090$ total number of recorded cells, from a total of 20 saline and microbead-injected eyes).

We compared the physiological responses from animals $15(n=5)$ or $30 \mathrm{~d}(n=5)$ after microbead injection with saline-injected controls. Microbead-injected animals used for the multielectrode recordings showed a significant increase in IOP that was detected as early as $1 \mathrm{~d}$ after the injection, which was sustained up until the day of recording $(p=0.0005$ and 0.0004 for 15 and $30 \mathrm{~d}$ groups, respectively, ANOVA one-way). The optokinetic response of the bead-injected eyes was already impaired significantly $15 \mathrm{~d}$ after injection (Fig. $2 C$, bottom; $p=0.002$ ), and remained perturbed until $30 \mathrm{~d}(p=0.008)$. Control eyes maintained normal 
values after saline injection $(p=0.5,0.06$, respectively, for 15 and $30 \mathrm{~d}$ groups, ANOVA one-way). In the recorded retinas, subsequent cell counts using TO-PRO3 showed that there was an average of $15.4 \pm$ $5.3 \%$ total cell loss in the RGC layer after $15 \mathrm{~d}(p=0.009)$ and $28.4 \pm 2.5 \%$ loss after $30 \mathrm{~d}\left(p=5 \times 10^{-5}\right)$.

Spontaneous activity was quantified for each RGC type as the average spike rate (Fig. 2D). Spontaneous firing rate was decreased in four of the five RGC types in the eyes injected with microbeads $30 \mathrm{~d}$ after bead injection. However, ON- and OFFsustained RGCs already showed significant reduction in their spontaneous activity $15 \mathrm{~d}$ after bead injection.

\section{Light response properties are}

\section{differentially impaired among RGCs}

The light responses of RGCs were further investigated using Gaussian white noise stimulation and reverse-correlation methods that enabled simultaneous evaluation of the spatial structure of the receptive field (RF) of neighboring cells (see Materials and Methods). Representative examples showing the spatial structure of the RF for each RGC type in saline-controls, 15 and $30 \mathrm{~d}$ after bead injection, are presented in Figure $3 A$. Quantification of the average RF radius (Fig. 3B) demonstrates that only OFF transient RGCs show a reduced RF size compared with control cells $(20.3 \pm 6.4 \% 30 \mathrm{~d}$ from injection). A significant change in RF size was detected as early as $15 \mathrm{~d}$ after bead injection (16.3 \pm $4.6 \%$ ). The other RGC categories showed no significant change in their average RF size even a month after bead-injection. For ON-OFF RGCs that are thought to be direction-selective, STA analysis of Gaussian white noise stimulation is not effective for investigating their receptive field properties (Cantrell et al., 2010; Koehler et al., 2011). Therefore, to assess the lightresponse of this cell type we used square wave stimuli, which more consistently drove the activity of this cell type. A significant reduction in the peak spiking rate at both the onset and offset of the light steps was detected from eyes injected with microbeads, $30 \mathrm{~d}$ after injection $(23.8 \pm 9.6 \%$ reduction at light onset, $p=0.002 ; 31.0 \pm$ $8.6 \%$ reduction at light offset, $p=0.017$, compared with control eyes).

To determine whether other functional response properties might have changed, we assessed the static nonlinear properties of the light response for the recorded RGCs by plotting the spike rate of each cell as a function of the generator signal (Fig. $4 A$; see Materials and Methods). The data points were fitted with a cumulative distribution function (see Materials and Methods) to obtain information

$\mathrm{B}$ colored band: SEM.
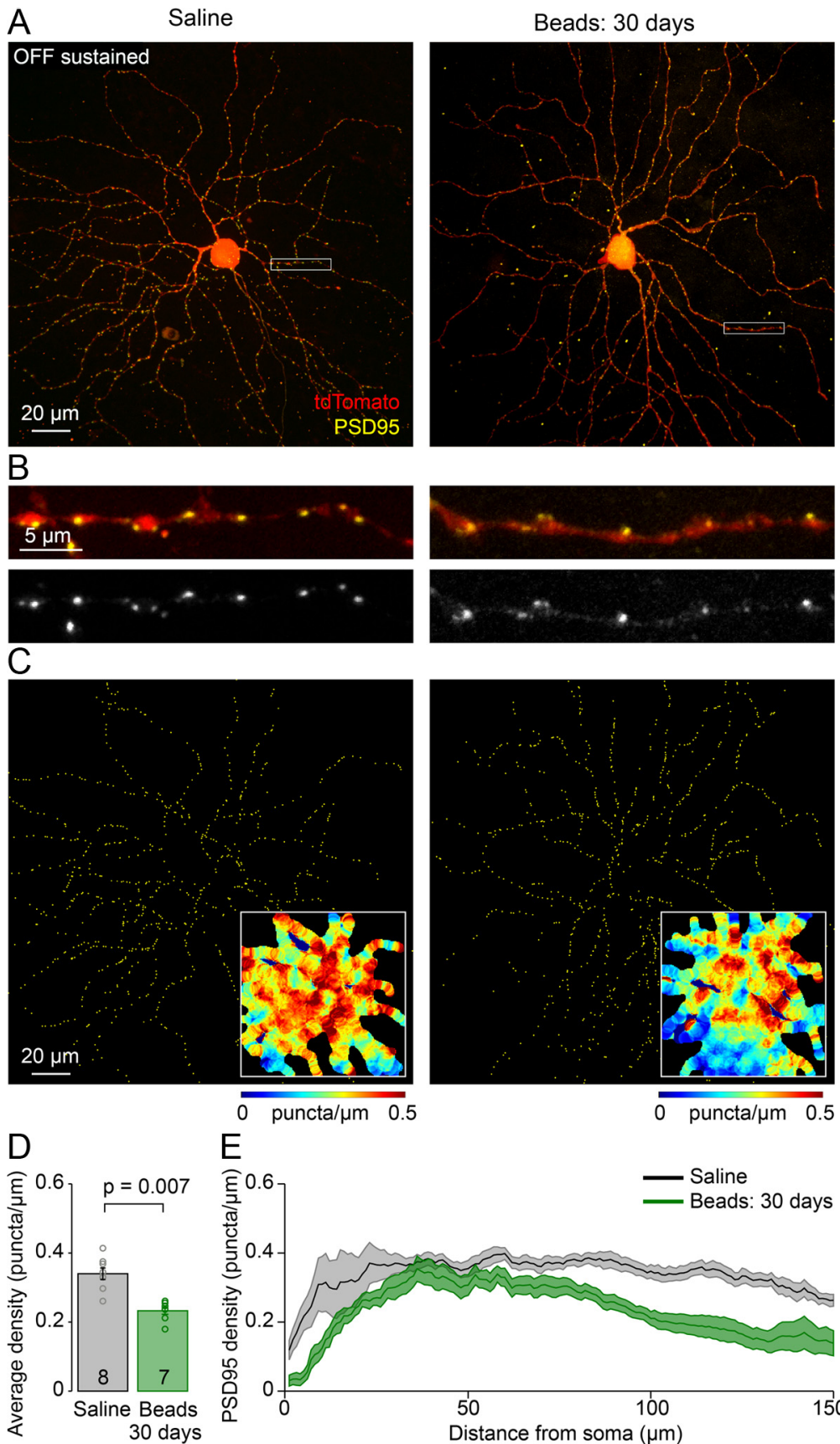

puncta/ $\mu \mathrm{m} \quad 0.5$

puncta/ $/ \mu \mathrm{m} \quad 0.5$

Figure 8. OFF-sustained RGCs show decreased synaptic density despite a normal dendritic morphology. $A$, Example of biolistically labeled OFF sustained RGCs in microbead-injected and control eyes showing coexpression of PSD95-CFP and tdTomato. $\boldsymbol{B}$, Bottom are magnified views of the dendrites in the boxed regions. C, Distribution of identified PSD95-CFP puncta, represented by yellow dots. Insets show "heat-maps" of the linear density of PSD95 of the cell. Hotter colors indicate higher density of PSD95 puncta. D, Average linear density of PSD95-CFP puncta of RGCs labeled in retinas obtained from animals in Figure 1. Cell numbers are noted on the histograms ( $n=5$ mice for each condition). Statistics: Wilcoxon-Mann-Whitney rank sum test. $\boldsymbol{E}$, Average linear density of PSD95-CFP puncta of the cells in $\boldsymbol{C}$, as a function of distance from the soma. Solid line: average value of sampled cells;

about spike threshold, gain, and maximal spike rate of the light response (Fig. $4 B-D$, respectively). We found that the light response properties of the various RGC types were not uniformly affected in the microbead-injected eyes. ON-sustained RGCs showed a progressive reduction of their maximal spike rate over time, concurrent with a gradual elevation of the spike threshold. OFF-sustained and -transient RGCs showed a progressive reduction of their maximal spike rate and gain of response, but no changes in their threshold. 
A

Saline

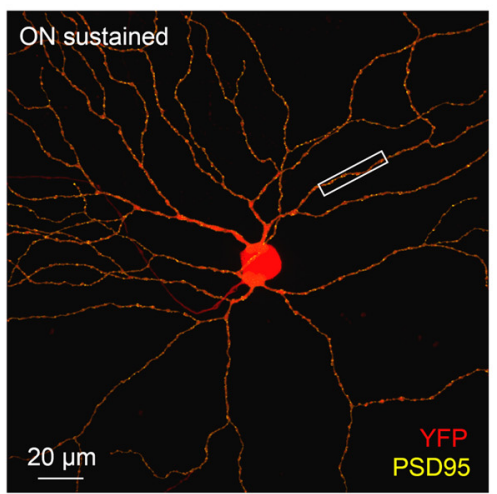

B
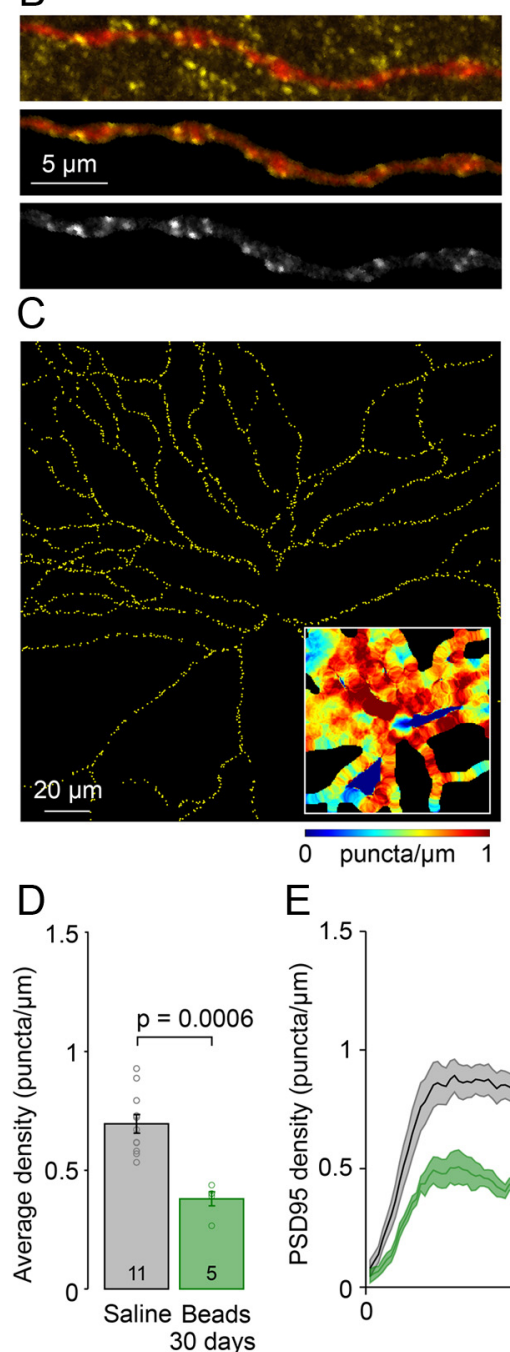

E

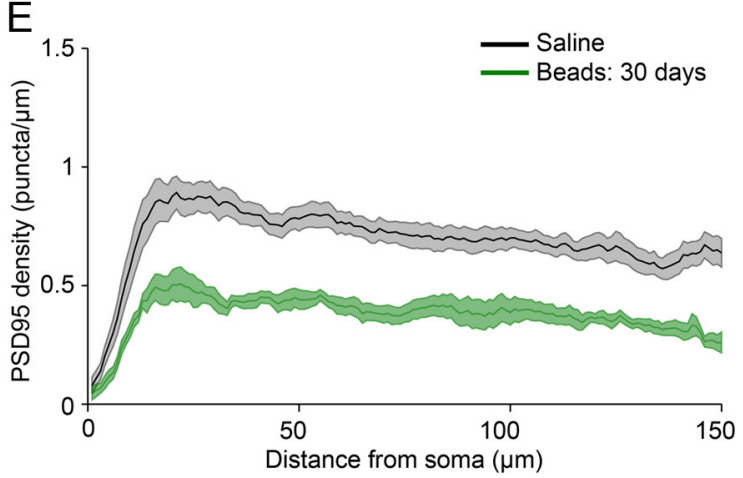

Figure 9. ON-sustained RGCs show decreased synaptic density despite normal dendritic morphology. $A$, Immunolabeled PSD95 on the dendrites of $0 \mathrm{~N}$-sustained RGCs across conditions. $\boldsymbol{B}$, Higher magnifications of the area within white rectangles in $\boldsymbol{A}$. Shown are as follows: (top) raw images of PSD95 labeling (yellow) and dendrites (red), (middle) PSD95 within the dendritic mask, and (bottom) PSD95 channel only (for masked dendrite). C, Distribution of PSD95 puncta. Each yellow dot is a punctum. Insets are heat map representations of the linear puncta density of the arbor. $\boldsymbol{D}$, Comparison of average linear density of cells from saline- and bead-injected eyes. Cell numbers are provided on the histograms ( $n=5$ mice each condition). Statistics: Wilcoxon-Mann-Whitney rank sum test. $\boldsymbol{E}$, Average linear density of PSD95 puncta for the cells in $\boldsymbol{D}$, plotted as a function of distance from the soma position.

Threshold changes could be due to a change in intrinsic excitability of the cell, fewer excitatory connections, alteration in the strength of existing excitatory synapses, or impaired bipolar cell light responses. Surprisingly, ON-transient RGCs were not significantly affected by
IOP elevation $(p=0.19,0.10,0.85$ for threshold, gain, maximum spike rate $30 \mathrm{~d}$ from injection, Wilcoxon-Mann-Whitney rank sum test). Finally, we did not find a strong correlation between each of the functional parameters measured and the magnitude of IOP elevation (Table 1). For example, a reduction in RF size of OFFtransient RGCs was not found preferentially in eyes with the highest IOP elevation; all eyes with $5 \mathrm{mmHg}$ or greater increase in IOP showed RF shrinkage.

\section{Dendritic arbor morphology of OFF- transient RGCs is selectively altered after IOP elevation}

We next asked whether in the recorded retinas there were morphological disruptions to the dendritic arbor of the RGC types that showed changes in their light responses. To avoid possible differences across mouse strains (Cone et al., 2010), our physiological recordings were performed in Thy1-YFPH transgenic mice (Feng et al., 2000), which have a sparse labeling of RGCs. This paucity of labeling enabled us to visualize individual dendritic arbors. Among the labeled cells, we examined large-field RGC types that correspond to the ON-sustained (A-Type ON-S), OFF-sustained (A-Type OFF-S), and OFF-transient (A-type OFF-T) RGCs (Pang et al., 2003; Murphy and Rieke, 2006; Margolis and Detwiler, 2007; van Wyk et al., 2009; Margolis et al., 2010). We did not examine the morphology of ONtransient RGCs because their morphological correlate is not yet determined in the mouse retina, in contrast to other species [cat: Cleland et al. (1975), monkey: Crook et al. (2008), gerbil: Luan et al. (2011), guinea pig: Demb et al. (2001)]. Also, we did not analyze ON-OFF RGCs because these RGCs are infrequently labeled in the Thyl-YFP line. Figure 5 provides examples of the RGC types that we reconstructed from saline-control and microbead-injected eyes.

OFF-transient RGCs showed a progressive reduction of their dendritic arbor size and complexity, which becomes significantly smaller than controls, $30 \mathrm{~d}$ after IOP elevation $(34.9 \pm 6.7 \%$ reduction of dendritic territory; Fig. $6 A, B)$. In contrast, OFF-sustained RGCs showed no difference in any of these morphological parameters after IOP elevation (Fig. $6 C$, $p=0.9,0.5,0.1$ for dendritic territory, length, and number after $30 \mathrm{~d}$, respectively). Moreover, Sholl analysis revealed no changes in the arborization patterns of these cells (Fig. 6D). Likewise, ONsustained RGCs also exhibited normal dendritic field structure in 


\begin{tabular}{|c|c|c|c|c|c|c|c|c|}
\hline \multirow{2}{*}{\multicolumn{2}{|c|}{ Ganglion cell }} & \multirow{2}{*}{$\begin{array}{c}\text { Spontaneous } \\
\text { activity }\end{array}$} & \multicolumn{3}{|c|}{ Light response } & \multicolumn{3}{|c|}{ Dendritic arbor } \\
\hline & & & \multirow{2}{*}{ Receptive field size } & Threshold & Gain / Max. Rate & \multirow{2}{*}{$\begin{array}{l}\text { Size } \\
\Rightarrow\end{array}$} & \multirow{2}{*}{$\begin{array}{c}\text { Complex. } \\
= \\
\end{array}$} & \multirow{2}{*}{$\frac{\text { PSD-95 }}{\downarrow}$} \\
\hline \multirow{2}{*}{ ON } & Sustained & $\downarrow \downarrow$ & & $\uparrow 4$ & $\downarrow \quad \downarrow$ & & & \\
\hline & Transient & $\rightleftharpoons$ & $\rightleftharpoons$ & $\Rightarrow$ & $\rightleftharpoons$ & N.A. & N.A. & N.A. \\
\hline \multirow{2}{*}{ OFF } & Sustained & $\downarrow \downarrow$ & $\rightleftharpoons$ & $\Rightarrow$ & & $\Rightarrow$ & $\Rightarrow$ & $\downarrow$ \\
\hline & Transient & $\rightleftharpoons \downarrow$ & $\downarrow \downarrow$ & $\Rightarrow$ & $\downarrow$ & $\Rightarrow \downarrow$ & $\Rightarrow \downarrow$ & $\downarrow$ \\
\hline
\end{tabular}

Figure 10. Summary of physiological and morphological alterations of various RGC types due to IOP elevation upon microbead injection.

bead-injected eyes despite pronounced functional alterations (Fig. $6 E, F ; p=0.7,0.7,0.9$ for dendritic territory, length, and number after $30 \mathrm{~d}$, respectively). The dendritic arbors of all these RGC types remained stratified in the microbead-injected eyes (Fig. 5).

\section{Synaptic connectivity of ON- and OFF-sustained RGCs is reduced before dendritic loss}

The reduction in the light-evoked responses of ON- and OFFsustained RGCs suggests that inputs onto these cells may be reduced, despite a relatively normal dendritic arbor, whereas reduction of synaptic inputs might happen concomitant to the dendritic arbor changes observed for OFF-transient RGCs. We thus analyzed the distribution of excitatory postsynaptic sites along the dendritic arbor of these RGC types to determine whether there were changes in connectivity despite a normal branching dendritic arbor. To visualize the excitatory input sites, we either immunolabeled retinas with anti-PSD95 or cotransfected CMV:PSD95-CFP. We then masked the dendritic signal and used it to isolate PSD95 puncta within the dendrites of selected RGCs from the surrounding neuropil (see Materials and Methods). OFF-transient RGCs that showed arbor shrinkage after $30 \mathrm{~d}$ of IOP elevation lost excitatory postsynaptic sites (Fig. $7 A, B)$. This synapse elimination is uniform across the dendritic arbor (Fig. 7C). Interestingly, OFF- and ON-sustained RGCs that demonstrated physiological changes but no obvious dendritic alteration also exhibited synapse loss throughout their dendritic arbors (Figs. $8 A-C, 9 A-C$, respectively). Thus, a reduction in excitatory postsynaptic sites appears to precede any detectable morphological changes in dendritic structure.

Our observations, summarized in Figure 10, indicate that the physiology and morphology of distinct types of RGCs are differentially affected by IOP elevation. Moreover, perturbations to the structure and function of the various RGC types studied occur on different time-scales.

\section{Discussion}

\section{Functional changes precede alterations to structure}

Previous studies across several species suggest that functional alterations to RGCs and in inner retinal neurons already occur before there is evidence of cell degeneration. Our physiological observations here extend previous ERG analysis of animal models of glaucoma (Saleh et al., 2007; Luo et al., 2011; Fortune et al., 2012) to single cell resolution, demonstrating that RGC function is compromised shortly after IOP elevation, before changes in dendritic morphology become apparent. We found a decrease in spontaneous firing across $\mathrm{ON}$ and OFF RGC types, reflecting reduced RGC excitability and/or a reduction in neurotransmission. The decreased firing rates contrasts with RGC hyperactivity found in other rodent models of retinal neurodegenerative diseases in which photoreceptors die (Sekirnjak et al., 2011; Stasheff et al., 2011). In fact, we did not observe oscillatory activity in RGCs that is characteristic of retinas with photoreceptor degeneration (Margolis and Detwiler, 2011). Thus, our current findings highlight a major difference in the perturbation of RGC function between retinas with IOP elevation and those with photoreceptor degeneration.

We also show that the light responses of RGCs are affected within 2 weeks after IOP elevation in the microbead injection model. The maximal spike rate of RGC light responses was reduced in most of the recorded RGC types, including those with no obvious morphological changes at that stage. In some RGCs, the gain and threshold of responses were also affected. The reduced connectivity and light-response of RGCs, together with possible rearrangements of their central connections, may underlie the impairment in optokinetic tracking. Loss of RGC synapses and alteration to light responses of the RGCs might occur together with dysfunction of their presynaptic neurons. A compensatory increase of the ERG b-wave amplitude was observed in the microbead model (Frankfort et al., 2013), while depression of the ERG a- and b-wave was reported in different animal models experiencing an higher magnitude of IOP elevation (Cuenca et al., 2010; Heiduschka et al., 2010). How physiological changes in the outer retina are manifested in RGC-spiking activity remains to be determined.

Finally, we discovered that the size of the functional receptive field of OFF-transient RGCs decreases before their dendritic arbor shrinks. We propose that dismantling of the receptive field is the last functional feature affected before morphological perturbations of dendrites are manifested. In contrast to another study using the Thy1-YFP line (Kalesnykas et al., 2012), we did not find an expansion of the dendritic arbors of surviving RGCs. This may be due to distinct criteria used to classify and compare RGCs between studies. Dendritic arbor expansion was also observed in a rat model of glaucoma (Ahmed et al., 2001), but this could reflect a species difference. Future work directly correlating structure and function of individual RGCs could help resolve these apparent differences across studies.

\section{Differential time-scale and nature of perturbation in specific RGC types}

It is evident from previous studies using different animal models of glaucoma that RGCs across the retina do not respond to IOP 
elevation uniformly. For example, cell death is often noticed to occur primarily in zonal sectors of the DBA/2J mouse model (Jakobs et al., 2005), but we did not find such sectorial death up to 1 month after microbead injection. Differences have also been observed in dendritic organization across RGC types. In the primate retina, parasol cells showed relatively greater dendritic loss compared with midget RGCs (Weber et al., 1998). Similarly, cat $\alpha$ RGCs show more severe dendritic loss than $\beta$ RGCs (Shou et al., 2003). In a previous study where IOP elevation exceeds that induced by microbeads injection, mouse ON RGCs but not ONOFF RGCs show dendritic shrinkage after 2 months (Feng et al., 2013). However, in this study OFF RGCs were not analyzed. Here, we also found that distinct functional types of mouse RGCs are affected differently by IOP elevation, and additionally show that this is evident as early as 2 weeks after injection. However, our study revealed that OFF-transient RGCs already show a concomitant loss of structure and function, when neighboring ON-transient RGCs remain normal in their physiology, although the latter cells may eventually die. This cell type difference did not appear to depend on RGC size, because the RGC type that appears to most rapidly degenerate (OFF transient) and the type that appears relatively resilient (ON transient) are both large-field cells. Moreover, how rapidly a RGC type shows signs of functional damage is not simply correlated with ON or OFF subclasses. Finally, it cannot be excluded at present that RGCs change their temporal response profile subsequent to IOP elevation.

The fact that ON- and OFF-sustained RGCs show a functional change before any detectable dendritic loss suggests that they may be at an intermediate level of damage. Indeed, we found a decrease in the density of glutamatergic postsynaptic sites for both these cell types. This loss of synapses correlates with a reduction in their spike rates. We currently do not know whether the synapses that are lost are only from one type of bipolar cell input or across all types of inputs. Our observations lead us to propose a plausible model for the sequence of changes in RGC dendrites in response to IOP elevation. We suggest that RGCs lose synapses leading to a reduction in spontaneous and evoked firing rates, followed by changes in receptive field sizes and pronounced dendritic loss. Reduction of synapses before major structural changes appears to be a common early feature across neurodegenerative diseases (Lacor et al., 2007; Yoshiyama et al., 2007). The early signs of RGC dendritic degeneration occur within the time frame of axonal impairment and loss reported in the microbead and other animal models of glaucoma (Fu and Sretavan, 2010; Chen et al., 2011). Whether or not degenerative events occur in the same sequence but at different time scales for each type of RGC, and whether synaptic loss is triggered by perturbations to RGC axons remains to be elucidated.

Why do some RGC types respond to increased IOP more quickly than others? Susceptibility to pressure in RGCs has been shown to be due to the expression of different classes of transient receptor potential vanilloid (TRPV) channels (Sappington et al., 2009). Activation of these channels influences neuronal firing properties and can induce apoptosis (Ryskamp et al., 2011). Differences in the density and type of TRPV channels expressed by RGCs may be one reason for their differential rate of response to elevated pressure. However, it is likely that other factors, even involving the activation of an immune response (Bakalash et al., 2002; Wax et al., 2008), could also cause one type of RGC to die more quickly than others.

\section{Implications for treatment}

Rodent models for open angle glaucoma differ in magnitude and range of IOP elevation, rapidity of cell death, and provoking of the inflammatory responses (Urcola et al., 2006; McKinnon et al., 2009). In our hands, microbead injections can cause transient or sustained, and relatively small IOP increases upon a single injection, which rapidly causes cell death. This contrasts with DBA/2J mice and humans, where death proceeds over a protracted and variable time course (Rangarajan et al., 2011). An advantage of the microbead model is that we can identify early changes in RGC function because death consistently occurs within 1-2 weeks after injection. Although several models focus on sustained IOP elevation (Shareef et al., 1995; Feng et al., 2013; Shimazawa et al., 2013), degeneration can continue even with transient IOP elevation (Ben Simon et al., 2006; Fu and Sretavan, 2010) or following the return of IOP to normal levels after treatment (Heijl et al., 2002). Indeed, glaucoma can also occur without any significant IOP increase in animals (Scholz et al., 2008; Harada et al., 2010) and in humans (Cheng et al., 2009). Thus, a more complete understanding of cellular changes that occur with or without IOP elevation is greatly needed.

For now, IOP-lowering agents represent one of the principal treatments for reestablishing normal IOP to limit the progression of glaucoma. Our findings here suggest that there is a critical period of time within which RGCs are functionally impaired but still preserve a relatively normal morphology. It will be important to determine whether reestablishing normal IOP within this time window is sufficient to reverse the functional impairment to the RGCs. At the same time, identifying the unique mechanisms that confer resistance to specific RGC types may be key to designing approaches to prevent further loss of RGCs in glaucoma. Our study underscores the importance of extending the current analytical approaches to other animal models and to humans. Knowing which RGC types become rapidly dysfunctional during onset of human disease will be crucial in developing an early functional screening method, as well as a more targeted therapy.

\section{References}

Ahmed FA, Chaudhary P, Sharma SC (2001) Effects of increased intraocular pressure on rat retinal ganglion cells. Int J Dev Neurosci 19:209-218. CrossRef Medline

Bakalash S, Kipnis J, Yoles E, Schwartz M (2002) Resistance of retinal ganglion cells to an increase in intraocular pressure is immune-dependent. Invest Ophthalmol Vis Sci 43:2648-2653. Medline

Baltan S, Inman DM, Danilov CA, Morrison RS, Calkins DJ, Horner PJ (2010) Metabolic vulnerability disposes retinal ganglion cell axons to dysfunction in a model of glaucomatous degeneration. J Neurosci 30: 5644-5652. CrossRef Medline

Ben Simon GJ, Bakalash S, Aloni E, Rosner M (2006) A rat model for acute rise in intraocular pressure: immune modulation as a therapeutic strategy. Am J Ophthalmol 141:1105-1111. CrossRef Medline

Buckingham BP, Inman DM, Lambert W, Oglesby E, Calkins DJ, Steele MR, Vetter ML, Marsh-Armstrong N, Horner PJ (2008) Progressive ganglion cell degeneration precedes neuronal loss in a mouse model of glaucoma. J Neurosci 28:2735-2744. CrossRef Medline

Calkins DJ (2012) Critical pathogenic events underlying progression of neurodegeneration in glaucoma. Prog Retin Eye Res 31:702-719. CrossRef Medline

Calkins DJ, Horner PJ (2012) The cell and molecular biology of glaucoma: axonopathy and the brain. Invest Ophthalmol Vis Sci 53:2482-2484. CrossRef Medline

Cantrell DR, Cang J, Troy JB, Liu X (2010) Non-centered spike-triggered covariance analysis reveals neurotrophin-3 as a developmental regulator of receptive field properties of ON-OFF retinal ganglion cells. PLoS Comput Biol 6:e1000967. CrossRef Medline

Chen H, Wei X, Cho KS, Chen G, Sappington R, Calkins DJ, Chen DF (2011) Optic neuropathy due to microbead-induced elevated intraocular pres- 
sure in the mouse. Invest Ophthalmol Vis Sci 52:36-44. CrossRef Medline

Cheng JW, Cai JP, Wei RL (2009) Meta-analysis of medical intervention for normal tension glaucoma. Ophthalmology 116:1243-1249. CrossRef Medline

Chichilnisky EJ (2001) A simple white noise analysis of neuronal light responses. Network 12:199-213. CrossRef Medline

Cleland BG, Levick WR, Wässle H (1975) Physiological identification of a morphological class of cat retinal ganglion cells. J Physiol 248:151-171. Medline

Cone FE, Gelman SE, Son JL, Pease ME, Quigley HA (2010) Differential susceptibility to experimental glaucoma among 3 mouse strains using bead and viscoelastic injection. Exp Eye Res 91:415-424. CrossRef Medline

Crook JD, Peterson BB, Packer OS, Robinson FR, Troy JB, Dacey DM (2008) Y-cell receptive field and collicular projection of parasol ganglion cells in macaque monkey retina. J Neurosci 28:11277-11291. CrossRef Medline

Cuenca N, Pinilla I, Fernández-Sánchez L, Salinas-Navarro M, AlarcónMartínez L, Avilés-Trigueros M, de la Villa P, Miralles de Imperial J, Villegas-Pérez MP, Vidal-Sanz M (2010) Changes in the inner and outer retinal layers after acute increase of the intraocular pressure in adult albino Swiss mice. Exp Eye Res 91:273-285. CrossRef Medline

Demas J, Eglen SJ, Wong RO (2003) Developmental loss of synchronous spontaneous activity in the mouse retina is independent of visual experience. J Neurosci 23:2851-2860. Medline

Demb JB, Zaghloul K, Haarsma L, Sterling P (2001) Bipolar cells contribute to nonlinear spatial summation in the brisk-transient $(\mathrm{Y})$ ganglion cell in mammalian retina. J Neurosci 21:7447-7454. Medline

Devries SH, Baylor DA (1997) Mosaic arrangement of ganglion cell receptive fields in rabbit retina. J Neurophysiol 78:2048-2060. Medline

Feng G, Mellor RH, Bernstein M, Keller-Peck C, Nguyen QT, Wallace M, Nerbonne JM, Lichtman JW, Sanes JR (2000) Imaging neuronal subsets in transgenic mice expressing multiple spectral variants of GFP. Neuron 28:41-51. CrossRef Medline

Feng L, Zhao Y, Yoshida M, Chen H, Yang JF, Kim TS, Cang J, Troy JB, Liu X (2013) Sustained ocular hypertension induces dendritic degeneration of mouse retinal ganglion cells that depends on cell type and location. Invest Ophthalmol Vis Sci 54:1106-1117. CrossRef Medline

Fortune B, Burgoyne CF, Cull GA, Reynaud J, Wang L (2012) Structural and functional abnormalities of retinal ganglion cells measured in vivo at the onset of optic nerve head surface change in experimental glaucoma. Invest Ophthalmol Vis Sci 53:3939-3950. CrossRef Medline

Frankfort BJ, Khan AK, Tse DY, Chung I, Pang JJ, Yang Z, Gross RL, Wu SM (2013) Elevated intraocular pressure causes inner retinal dysfunction before cell loss in a mouse model of experimental glaucoma. Invest Ophthalmol Vis Sci 54:762-770. CrossRef Medline

Fu CT, Sretavan D (2010) Laser-induced ocular hypertension in albino CD-1 mice. Invest Ophthalmol Vis Sci 51:980-990. CrossRef Medline

Harada C, Namekata K, Guo X, Yoshida H, Mitamura Y, Matsumoto Y, Tanaka K, Ichijo H, Harada T (2010) ASK1 deficiency attenuates neural cell death in GLAST-deficient mice, a model of normal tension glaucoma. Cell Death Differ 17:1751-1759. CrossRef Medline

Heiduschka P, Julien S, Schuettauf F, Schnichels S (2010) Loss of retinal function in aged DBA/2J mice-New insights into retinal neurodegeneration. Exp Eye Res 91:779-783. CrossRef Medline

Heijl A, Leske MC, Bengtsson B, Hyman L, Bengtsson B, Hussein M, Early Manifest Glaucoma Trial Group (2002) Reduction of intraocular pressure and glaucoma progression: results from the Early Manifest Glaucoma Trial. Arch Ophthalmol 120:1268-1279. CrossRef Medline

Howell GR, Libby RT, Jakobs TC, Smith RS, Phalan FC, Barter JW, Barbay JM, Marchant JK, Mahesh N, Porciatti V, Whitmore AV, Masland RH, John SW (2007) Axons of retinal ganglion cells are insulted in the optic nerve early in DBA/2J glaucoma. J Cell Biol 179:1523-1537. CrossRef Medline

Jakobs TC, Libby RT, Ben Y, John SW, Masland RH (2005) Retinal ganglion cell degeneration is topological but not cell type specific in DBA/2J mice. J Cell Biol 171:313-325. CrossRef Medline

Jeon CJ, Strettoi E, Masland RH (1998) The major cell populations of the mouse retina. J Neurosci 18:8936-8946. Medline

Kalesnykas G, Oglesby EN, Zack DJ, Cone FE, Steinhart MR, Tian J, Pease ME, Quigley HA (2012) Retinal ganglion cell morphology after optic nerve crush and experimental glaucoma. Invest Ophthalmol Vis Sci 53: 3847-3857. CrossRef Medline

Kerschensteiner D, Liu H, Cheng CW, Demas J, Cheng SH, Hui CC, Chow RL, Wong RO (2008) Genetic control of circuit function: Vsx1 and Irx5 transcription factors regulate contrast adaptation in the mouse retina. J Neurosci 28:2342-2352. CrossRef Medline

Koehler CL, Akimov NP, Rentería RC (2011) Receptive field center size decreases and firing properties mature in ON and OFF retinal ganglion cells after eye opening in the mouse. J Neurophysiol 106:895-904. CrossRef Medline

Lacor PN, Buniel MC, Furlow PW, Clemente AS, Velasco PT, Wood M, Viola KL, Klein WL (2007) Abeta oligomer-induced aberrations in synapse composition, shape, and density provide a molecular basis for loss of connectivity in Alzheimer's disease. J Neurosci 27:796-807. CrossRef Medline

Longair MH, Baker DA, Armstrong JD (2011) Simple Neurite Tracer: open source software for reconstruction, visualization and analysis of neuronal processes. Bioinformatics 27:2453-2454. CrossRef Medline

Luan L, Ren C, Lau BW, Yang J, Pickard GE, So KF, Pu M (2011) Y-like retinal ganglion cells innervate the dorsal raphe nucleus in the Mongolian gerbil (Meriones unguiculatus). PLoS ONE 6:e18938. CrossRef Medline

Luo X, Patel NB, Harwerth RS, Frishman LJ (2011) Loss of the lowfrequency component of the global-flash multifocal electroretinogram in primate eyes with experimental glaucoma. Invest Ophthalmol Vis Sci 52:3792-3804. CrossRef Medline

Margolis DJ, Detwiler PB (2007) Different mechanisms generate maintained activity in ON and OFF retinal ganglion cells. J Neurosci 27:59946005. CrossRef Medline

Margolis DJ, Detwiler PB (2011) Cellular origin of spontaneous ganglion cell spike activity in animal models of retinitis pigmentosa. J Ophthalmol pii: 507037. Medline

Margolis DJ, Gartland AJ, Euler T, Detwiler PB (2010) Dendritic calcium signaling in ON and OFF mouse retinal ganglion cells. J Neurosci 30: 7127-7138. CrossRef Medline

Masland RH (2001) The fundamental plan of the retina. Nat Neurosci 4:877-886. CrossRef Medline

Mattson DL (2001) Comparison of arterial blood pressure in different strains of mice. Am J Hypertens 14:405-408. CrossRef Medline

McKinnon SJ, Schlamp CL, Nickells RW (2009) Mouse models of retinal ganglion cell death and glaucoma. Exp Eye Res 88:816-824. CrossRef Medline

Morgan JL, Schubert T, Wong RO (2008) Developmental patterning of glutamatergic synapses onto retinal ganglion cells. Neural Dev 3:8. CrossRef Medline

Murphy GJ, Rieke F (2006) Network variability limits stimulus-evoked spike timing precision in retinal ganglion cells. Neuron 52:511-524. CrossRef Medline

Nadal-Nicolás FM, Jiménez-López M, Sobrado-Calvo P, Nieto-López L, Cánovas-Martínez I, Salinas-Navarro M, Vidal-Sanz M, Agudo M (2009) Brn3a as a marker of retinal ganglion cells: qualitative and quantitative time course studies in naive and optic nerve-injured retinas. Invest Ophthalmol Vis Sci 50:3860-3868. CrossRef Medline

Pang IH, Clark AF (2007) Rodent models for glaucoma retinopathy and optic neuropathy. J Glaucoma 16:483-505. CrossRef Medline

Pang JJ, Gao F, Wu SM (2003) Light-evoked excitatory and inhibitory synaptic inputs to ON and OFF alpha ganglion cells in the mouse retina. J Neurosci 23:6063-6073. Medline

Pascolini D, Mariotti SP (2012) Global estimates of visual impairment: 2010. Br J Ophthalmol 96:614-618. CrossRef Medline

Pavlidis M, Stupp T, Naskar R, Cengiz C, Thanos S (2003) Retinal ganglion cells resistant to advanced glaucoma: a postmortem study of human retinas with the carbocyanine dye DiI. Invest Ophthalmol Vis Sci 44:51965205. CrossRef Medline

Prusky GT, Alam NM, Beekman S, Douglas RM (2004) Rapid quantification of adult and developing mouse spatial vision using a virtual optomotor system. Invest Ophthalmol Vis Sci 45:4611-4616. CrossRef Medline

Rangarajan KV, Lawhn-Heath C, Feng L, Kim TS, Cang J, Liu X (2011) Detection of visual deficits in aging DBA/2J mice by two behavioral assays. Curr Eye Res 36:481-491. CrossRef Medline

Rasmussen CA, Kaufman PL (2005) Primate glaucoma models. J Glaucoma 14:311-314. CrossRef Medline

Ryskamp DA, Witkovsky P, Barabas P, Huang W, Koehler C, Akimov NP, Lee 
SH, Chauhan S, Xing W, Rentería RC, Liedtke W, Krizaj D (2011) The polymodal ion channel transient receptor potential vanilloid 4 modulates calcium flux, spiking rate, and apoptosis of mouse retinal ganglion cells. J Neurosci 31:7089-7101. CrossRef Medline

Saleh M, Nagaraju M, Porciatti V (2007) Longitudinal evaluation of retinal ganglion cell function and IOP in the DBA/2J mouse model of glaucoma. Invest Ophthalmol Vis Sci 48:4564-4572. CrossRef Medline

Sanes JR, Zipursky SL (2010) Design principles of insect and vertebrate visual systems. Neuron 66:15-36. CrossRef Medline

Sappington RM, Sidorova T, Long DJ, Calkins DJ (2009) TRPV1: contribution to retinal ganglion cell apoptosis and increased intracellular $\mathrm{Ca}^{2+}$ with exposure to hydrostatic pressure. Invest Ophthalmol Vis Sci 50:717728. Medline

Sappington RM, Carlson BJ, Crish SD, Calkins DJ (2010) The microbead occlusion model: a paradigm for induced ocular hypertension in rats and mice. Invest Ophthalmol Vis Sci 51:207-216. CrossRef Medline

Schneider CA, Rasband WS, Eliceiri KW (2012) NIH Image to ImageJ: 25 years of image analysis. Nat Methods 9:671-675. CrossRef Medline

Scholz M, Buder T, Seeber S, Adamek E, Becker CM, Lütjen-Drecoll E (2008) Dependency of intraocular pressure elevation and glaucomatous changes in DBA/2J and DBA/2J-Rj mice. Invest Ophthalmol Vis Sci 49:613-621. CrossRef Medline

Segev R, Puchalla J, Berry MJ 2nd (2006) Functional organization of ganglion cells in the salamander retina. J Neurophysiol 95:2277-2292. Medline

Sekirnjak C, Jepson LH, Hottowy P, Sher A, Dabrowski W, Litke AM, Chichilnisky EJ (2011) Changes in physiological properties of rat ganglion cells during retinal degeneration. J Neurophysiol 105:25602571. CrossRef Medline

Shareef SR, Garcia-Valenzuela E, Salierno A, Walsh J, Sharma SC (1995) Chronic ocular hypertension following episcleral venous occlusion in rats. Exp Eye Res 61:379-382. CrossRef Medline

Shimazawa M, Nakamura S, Miwa M, Tsuruma K, Aihara M, Nakamura K, Hara H (2013) Establishment of the ocular hypertension model using the common marmoset. Exp Eye Res 111:1-8. CrossRef Medline

Shou T, Liu J, Wang W, Zhou Y, Zhao K (2003) Differential dendritic shrinkage of alpha and beta retinal ganglion cells in cats with chronic glaucoma. Invest Ophthalmol Vis Sci 44:3005-3010. CrossRef Medline

Sommer A (1989) Intraocular pressure and glaucoma. Am J Ophthalmol 107:186-188. Medline

Soto I, Oglesby E, Buckingham BP, Son JL, Roberson ED, Steele MR, Inman DM, Vetter ML, Horner PJ, Marsh-Armstrong N (2008) Retinal ganglion cells downregulate gene expression and lose their axons within the optic nerve head in a mouse glaucoma model. J Neurosci 28:548-561. CrossRef Medline

Stasheff SF, Shankar M, Andrews MP (2011) Developmental time course distinguishes changes in spontaneous and light-evoked retinal ganglion cell activity in rd1 and rd10 mice. J Neurophysiol 105:3002-3009. CrossRef Medline

Tian N, Copenhagen DR (2001) Visual deprivation alters development of synaptic function in inner retina after eye opening. Neuron 32:439-449. CrossRef Medline

Urcola JH, Hernández M, Vecino E (2006) Three experimental glaucoma models in rats: comparison of the effects of intraocular pressure elevation on retinal ganglion cell size and death. Exp Eye Res 83:429-437. CrossRef Medline

van Wyk M, Wässle H, Taylor WR (2009) Receptive field properties of ONand OFF-ganglion cells in the mouse retina. Vis Neurosci 26:297-308. CrossRef Medline

Wässle H (2004) Parallel processing in the mammalian retina. Nat Rev Neurosci 5:747-757. CrossRef Medline

Wax MB, Tezel G, Yang J, Peng G, Patil RV, Agarwal N, Sappington RM, Calkins DJ (2008) Induced autoimmunity to heat shock proteins elicits glaucomatous loss of retinal ganglion cell neurons via activated T-cellderived fas-ligand. J Neurosci 28:12085-12096. CrossRef Medline

Weber AJ, Kaufman PL, Hubbard WC (1998) Morphology of single ganglion cells in the glaucomatous primate retina. Invest Ophthalmol Vis Sci 39:2304-2320. Medline

Yoshiyama Y, Higuchi M, Zhang B, Huang SM, Iwata N, Saido TC, Maeda J, Suhara T, Trojanowski JQ, Lee VM (2007) Synapse loss and microglial activation precede tangles in a P301S tauopathy mouse model. Neuron 53:337-351. CrossRef Medline 